\title{
CONF-276-1
}

Deformation Twinning in Face-Centered Cubic Metals

\section{J. A. Venables}

Department of Physics, University of Illinois Urbana, Illinois

Facsimile Price $\$$

Microfilm Price \$

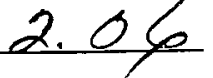

Available from the

Office of Technical Services

Department of Commerce

Washington 25, D: C.

To be presented at the Conference on Deformation Twinning

Gainesville, Florida, March 21-22, 1963

\section{LEGAL NOTICE} of Goveramest spossored work. Nelter

A. Makes any warranty or representation, expressed or implied, with respect to the accuracy, completeness, or usefulness of the information conthed in int report may not infringe

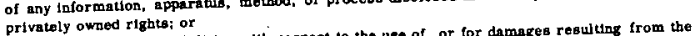

B. Assumes any liabilttes with respect to the use of. or for damages resil.

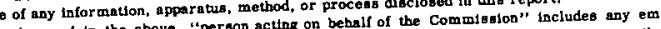
Ae Duch employee or contractor of the Commissios, or employee of suct contractor propatros with the commitsion, or his employment 


\section{DISCLAIMER}

This report was prepared as an account of work sponsored by an agency of the United States Government. Neither the United States Government nor any agency Thereof, nor any of their employees, makes any warranty, express or implied, or assumes any legal liability or responsibility for the accuracy, completeness, or usefulness of any information, apparatus, product, or process disclosed, or represents that its use would not infringe privately owned rights. Reference herein to any specific commercial product, process, or service by trade name, trademark, manufacturer, or otherwise does not necessarily constitute or imply its endorsement, recommendation, or favoring by the United States Government or any agency thereof. The views and opinions of authors expressed herein do not necessarily state or reflect those of the United States Government or any agency thereof. 


\section{DISCLAIMER}

Portions of this document may be illegible in electronic image products. Images are produced from the best available original document. 
Deformation Twinning in Face-Centered Cubic Metals

by

J.A. Venables

February, 1963

Technical Report No. 1

$$
\operatorname{AT}(11-1)-1198(\mathrm{~K}) \text {. }
$$

J. S. Koehler

Senior Investigator

Department of Physics

University of Illinois

Urbana, Illinois 


\section{Contents}

Introduction

1. Experiments on Deformation Twinning in f.c.c. Metals and Alloys

1.1 Experimental Evidence for the Existence of Deformation Twins.

1.2 Characteristics of Deformation Twins.

1.3 The Stresses Required for Twinning.

2. Dislocations and Twin Nucleation

2.1 The Geometry of Twinning in f.c.c. Crystals.

2.2 Dislocation Reactions Leading to Twinning.

3. Calculations of the Twin Stress

3.1 The Workhardened State.

3.2 Stresses for Twin Nucleation:

3.3 The Propagation of Deformation Twins.

Conclusion

Acknowledgments

References 


\section{Introduction}

This review of work on deformation twinning in f.c.c. metals is divided into three parts. The first section concerns the experiments which have been performed on several metals and alloy systems. In Section 1.1 experiments which prove the existence of deformation twins are described; in section 1.2 the characteristics of the twins are reviewed; and, in section 1.3 the stresses required for their production are analysed. Section 2 reviews the dislocation models which have been proposed to account for the nucleation of deformation twins in f.c.c.metals. The third and last section is in the nature of a discussion and does not pretend to answer all the questions that are raised; however, it is felt that unless an attempt is made to formulate in simple physical terms the problems posed by deformation twinning, experimenters in the field will lack a motive, and consequently less will be achieved. It is hoped that this section will at least provide a stimulus to others to tackle problems of a similar nature. 


\subsection{Experimental Evidence for the Existence of Deformation Twins.}

The first suggestions that twinning is a mode of deformation in face-centered cubic metals and alloys came from early experiments on the nature of slip lines in a-brass, notably by Mathewson and co-workers. $1,2 /$ At that time, no direct $x$-ray evidence was available, and the arguments were based solely on the straightness of the slip lines, and the fact that the recrystallization of the deformed a-brass specimens produced annealing twins exactly similar to those seen in as-grown specimens.

The first $x$-ray evidence for twinning in ambass, and until recently $3 /$ the only evidence, was obtained by samans. 4 / He used a double film method (the Davey-Wilson method ${ }^{2}$ ), which enabled him to identify the badly defined spots from the highly deformed twin and matrix lattices. The two cases he examined agreed well with the assumption of normal twinning on $[111\}$ planes in the matrix. Burke and Barrett, $6 /$ however, repeated Samans' experiments and concluded that twins were not produced in the cold working of $\alpha$-brass. They also deduced that the coarse slip lines, thought to contain twins by samans and Mathewson, must be mainly caused by glide and not twinning, as the strain in them was too large by as much as a factor of ten. 
More recent work on abrass, particularly by warren and associates, I/ has been confined to measurements of the shape and displacements of powder pattern lines from deformed filings. These results were analysed by methods similar to those of Patterson $8 /$ and Méring $9 /$ and gave values of the probability density of stacking faults and twin boundaries. The results of the analysis of $x$-ray powder patterns depend on the model adopted for the interior of the cold-worked metal. Wagner $10 /$ assumed that there was a random distribution of both stacking faults and twin boundaries. He concluded that both single stacking faults and pairs of twin boundaries occurred with equal probability in the cold-worked metal, the faulting probability being about five times greater in 65-35 brass than in pure copper. It is not immediately obvious what effect clustering of faults into fine twins should have on the position and shape of the reflected x-ray lines: but the density of faults and twins observed in the most heavily deformed tensile specimens might be expected to be of the same order of magnitude as the density deduced from the $x$-ray measurements on filings. As a detector of small amounts of faulting and twinning, the x-ray powder methods are not sensitive enough and are open to several interpretations. More recently, wide faults have been shown to be present in many metals, including $\alpha$-brass, using the electron microscope. $11,12,13,14 / \cdots$ An electron microscope study of deformation twinning has been published (in outline) by the present author.15,16/ 
Since 1957, many reports of deformation twinning in tensile specimens of f.C.C. metals and alloys have appeared. Blewitt, Coltrian and Redman $12 /$ found .. single crystals of copper of certain orientations to twin at high stresses in liquid helium, and for a more restricted range of tensile axis orientations in liquid nitrogen. Suzuki and Barrett 18 found similar behavior in the whole range of silver-gold alloys and Haasen $19 /$ reported that nickel single crystals twinned at both 4.2 and $20^{\circ} \mathrm{K}$. Thornton and Mitchel1 $3 /$ have investigated the $\alpha$-brass system and the present author $15,16 /$ has published preliminary accounts of work on $\mathrm{Cu}+\mathrm{Al}$ alloys. Haasen and $\mathrm{King} 20 /$ have found deformation twinning in $\mathrm{Cu}+\mathrm{Ge}$ and $\mathrm{Cu}+\mathrm{Ga}$ single crystals of a standard orientation in tests at up to $200^{\circ} \mathrm{C}$. It has been found that both aluminum and lead do not twin at the highest stresses reached at low temperatures. $3,17,19,21$

Blewitt, et al. $17 /$ and suzuki and Barrett $18 /$ used special $x$-ray methods to detect the twinning. Blewitt, et al. used an

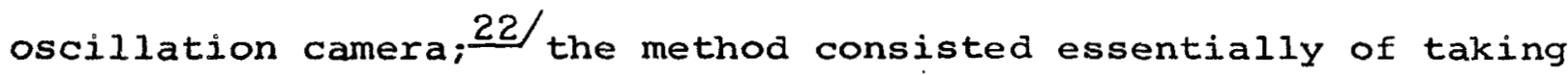
rocking curves in prominent matrix zones and looking for extra reflections with a Geiger counter. In this way, twin reflections could be recorded and identified by their angular separation. Suzuki and Barrett used a two film Weissenberg method similar to that of Samans. $4 /$ Thornton and Mitchel1 $3 /$ and the present author have been able to identify the twins by back-reflection Laue photographs in certain cases. Twins can be easily identified in 
thin metal foils in the electron microscope using the technique of selected area diffraction. An example, due to the author, $15 /$ is given in Fig. 1 . Both twin and matrix lattices are in $\{110\}$ orientations which are related to each other by a rotation of $180^{\circ}$ about the twin plane normal $t$.

The twinning direction has been established, both by direct measurements of the twinning shear 17 and by the rotation of the tensile axis during twinning: $20 /$ it has been found to be [112] in the (1II) primary twin plane and [112] in the conjugate plane $(1 \overline{1} 1)$. 


\subsection{Characteristics of Deformation Twins.}

The metals and alloys studied have several features

of their twinning behavior in common, which will now be considered.

In the metals $\mathrm{Cu}$ and $\mathrm{Ni}$, andithe alloy systems $\mathrm{Ag}+\mathrm{Au}$, $\mathrm{Cu}+\mathrm{Zn}(0$ to 20 percent $\mathrm{Zn}), \mathrm{Cu}+\mathrm{Ge}(0$ to $6.6 \mathrm{at}$. percent $\mathrm{Ge})$, $\mathrm{Cu}+\mathrm{Ga}(0$ to 10 at percent $\mathrm{Ga}$ ) and $\mathrm{Cu}+\mathrm{Al}$ ( 0 to 8 at, percent Al) twinning occurs only under a high resolved shear stress. The stress is typically $15 \mathrm{~kg} \cdot \mathrm{mm}^{-2}$ for $\mathrm{Cu}$, up to $30 \mathrm{~kg} \cdot \mathrm{mm}^{-2}$ in $\mathrm{Ni}, 5$ to $10 \mathrm{~kg} \cdot \mathrm{mm}^{-2}$ in the $\mathrm{Ag}+\mathrm{Au}$ allows, and more than $6 \mathrm{~kg} \cdot \mathrm{mm}^{-2}$ in the copper solid solutions. Because these high stresses are necessary, twinning is not (except in the case of Ag and some Cu base alloys) a deformation made at room temperature, which explains why earlier experimenters failed to find deformation twins. For instance about 75 percent extension of a copper single crystal at $4.2^{\circ} \mathrm{K}$ is necessary for the metal to harden sufficiently to reach the twin stress. When the twin stress is reached, a macroscopic band of twin forms, accompanied by a sudden load drop, and thereafter the band of twin grows jerkily under decreased load until the twinned region fills the specimen. From there on the specimen may work-harden again until it fractures. The load drop, marking the onset of twinning on a macroscopic scale can therefore be used to investigate the variation of the twin stress with such variables as temperature, orientation and composition of an alloy system. The value of the twin stress so obtained varies widely for apparently similarly 
treated crystals and Blewitt, et al.17/did not think that a resolved shear stress criterion was significant. However, the other authors quoted have given values of the critical resolved shear stress for twinning, obtained from observed load drops for the $\mathrm{Ag}+\mathrm{Au}$, $\mathrm{Cu}+\mathrm{Ga}$, and $\mathrm{Cu}+\mathrm{Zn}$ systems. They havefound that the composition of the alloy was the only significant variable in determining

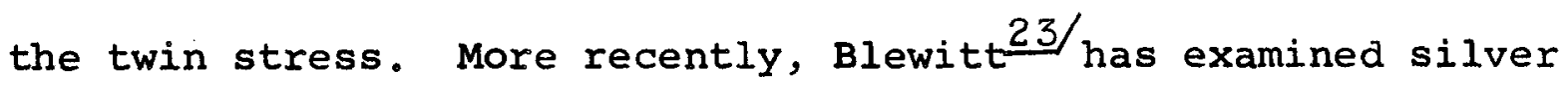
and found evidence for a variation of the twin stress with orientation and temperature. In section 1.3 the available data on the twin stress is collected and analysed for possible variations with temperature and orientation.

The main differences in twinning behavior lie in the mode of propagation of the twins. Blewitt, et al. I/ found copper to twin in most cases on the primary slip plane only, and the twin propagated as in Lilders band throughout the specimen. In a special case where the initial tensile axis was very near the (100)-(111) zone, twinning occurred on both primary and conjugate slip planes. In an irradiated specimen the twin plane was the conjugate slip plane.

Fig. $2(a)$ is a composite photograph of the various stages of twin growthin copper. I/ Picture 1 shows the start of a neck just before the load drop, and the formation of the twin band is, shown in 2. Pictures 2, 3 and 4 show the twin filling the material, propagating as a Irthders band under an unsteady load, which is constant on the average. The specimen then hardened until it fractured (picture 7 ). 
with a special $x$-ray technique it was shown in a similar sample, that the Milters band consists of two crystals, the twin and the parent crystals in roughly equal amounts. 22/ Fig. 2(b) shows an electron micrograph of a twinned crystal of copper 16/ showing that the wide and narrow twins at $A$ and $B$ account for somewhat less than 50 percent of the volume of the Ltders band. The individual twins were never wider than 5000A; and some of these wide twins could be seen to be formed by coalescence of finer ones. Each individual twin of this: width has a length of a few hundred microns (measured optically), and so probably spanned the width of the thin specimen. This length to thickness ratio is several hundred which is consistent with the theory that the shape of the twin is governed by the back stress produced by the twinning shear. 15,24/ Thus, the macroscopic twin bands observed by Blewitt, et al. 17 and by suzuki and Barrett $18 /$ contain very many individual fine twin lamellae. Suzuki and Barrett $\frac{18}{2}$ have made the most detailed study of twin propagation to date and they found three different types of propagation in their samples of Ag + A Type $I$ twinning, which was the highest temperature mode, started with the appearance of a single localized band of twin on either the primary or the conjugate plane. This band of twin then grew into (say) the upper right-hand and lower left-hand quadrants of the specimen and twins on the conjugate system formed in the other two quadrants. Suzuki and Barrett explain this in terms of the bending moments 
which appear at the interface of the initially formed twin, which will favor the production of the conjugate twins in that neighborhood.

The second type of twinning observed,aat lower temperatures in the silver rich alloys, showed production of bands of twin in the two conjugate orientations in different parts of the specimen. These separate bands then grew until they reached each other.

In the third class of crystals, the silver rich alloys at the lowest temperatures, twinning took place on both conjugate planes throughout the crystal and there was no localized flow. The type of twinning exhibited varied systematically with both composition and temperature of testing. The observations, taken from their paper, are reproduced in Fig. 3(a). Blewitt23/ has indicated that type III twinning in his silver crystals was confined to two crystals which twinned at the lowest stresses. The other crystals twinned with the formation of a LIdders band. Both Haasen and $\mathrm{King} 20 /$ and Thornton and Mitchel1 $3 /$ found that the conjugate slip plane was the most commonly observed twin plane in the copper solid solutions."The primary twin plane was also observed. The author has found that these twin planes occur in $\mathrm{Cu}+\mathrm{Al}$ alloys and that at high aluminum content ( $\geq 8$ at percent AI) twins also form on the critical slip plane. Nickell/ has twinned on the primary, conjugate and critical slip planes, although the critical plame has only been observed (once) in the neck of a fractured specimen. In no cases have twins on the cross-slip plane been reported. 
From the work on copper and silver-gold alloys, it is apparent that the magnitude of the load drops varies with temperature and composition in a way which may be connected with the type of twin propagation observed. The stress-strain curves of an Ag +25 percent An crystal which showed all three types of twinning behavior at different temperatures are shown in Fig. 6. There is at least a large difference in the size of the load drops on the curves for 20.4 and $77.3^{\circ} \mathrm{K}$, and in general, the size increases with temperature. Very similar variations of load drop with temperatures have been found by Thornton and Mitchell for $\mathrm{Cu}+20$ percent $\mathrm{Zn}$. At room temperature, the drop was about 10 percent of the load whereas in liquid helium the stress-strain curve was perfectly smooth. A similar transition in the propagation characteristics with temperature has been observed in $\mathrm{Cu}+9.66$ at. percent Ge between $295^{\circ}$ and $82^{\circ} \mathrm{K}, \underline{20 /}$ and in $\mathrm{Cu}+7$ at. percent $\mathrm{Al}$ between $77^{\circ} .3$ and $4.2^{\circ} \mathrm{K} . \underline{25 /}$ In copper alloys containing more than 20 percent $\mathrm{zn}$ or 8 at percent $A l$, no load drops have been observed at any testing temperature.

The present author has. showr $15,16 /$ that twins are formed in profusion in the concentrated alloys; therefore, the lack of load drops on the stress-strain curve must indicate that twins, once nucleated, cannot propagate freely through the crystal. This idea is supported by electron microscope observations. In contrast to the observations on pure copper, when twins are 
produced with load drops, the growth of twins from single stacking faults can be followed, when the stress-strain curves are smooth, by examining specimens at increasing stress levels. Fig. 4(a) to (c) shows such a sequence of micrographs of three different crystals ofCu +8.9 . at.percent Al of the same orientation, when the resolved shear stresses for twinning were 5.5,7.3 and $9.0 \mathrm{~kg} . \mathrm{mm}^{-2}$ respectively. At the lowest stresses faults form [as at A, Fig. 4(a)] on the primary and conjugate slip planes. In Fig. 4(b), two twins (giving well defined twin reflections) on the conjugate slip plane are seen and in Fig. $4(c)$ the twins are piled up against each other on the conjugate and critical slip plane. Twins on the critical slip plane at a stress of $26 \mathrm{~kg} \cdot \mathrm{mm}^{-2}$ in the same alloy are shown in Fig l(a). The twins are stupped at boundaries of twins on other systems. The twins in Fig。 4(b) end in the crystal and have apparently been stopped by interacting with the dislocation forest. Twins in these alloys were often observed to have dislocations in the boundaries lying along the direction common to the twin plane and the conjugate slip plane. Slip dislocations can interact along this direction with twin dislocations to form Frank partiall dislocations. In my opinion, the occurrence of this dislocation reaction, the reverse of the reaction leading to the nucleation of twins (Section 2.2), is the reason that twins are stable when the stress is removed. Thus, it is seen that twins in these concentrated alloys form slowly from single stacking faults as the 
stress is increased. In the less concentrated alloys, the twinning is controlled solely by nucleation; copper crystals have been examined by the author at stresses just below those at which the load drops were expected to occur, and no twins were detected in the electron microscope. Thus, we may have confidence in ascribing the onset of the load drops as the applied stress required to nucleate a twin. In the higher concentrate range, the lowest stress at which wide faults are observed in the electron microscope is a more appropriate value for the twin stress. In the next section, values of the twin stress are presented. They are correlated, in particular, with composition in the alloy systems. Composition is thought to be important primarily because of variations in the stacking fault energy, and it is in terms of this variable that the data are plotted in the next section. 


\subsection{The Stresses Reguired for Twirning.}

The data in this section will be presented, where possible, in terms of the variation of twin stress with temperature, orientation, and stacking fault energy. stacking fault energies have been measured by Howie and swann $26 /$ using the radius of curvature of certain dislocation nodes observed in the electron microscope, a method first suggested by whelan.12/ Their values have been corrected (for the interaction of the partial dislocations in the nodel by siems et al. $27 /$ and republished by Thornton et al. 28/ The values are plotted in Fig. 5 as a function of the electron to atom ratio (e/a) for the systems of interest, $\mathrm{Cu}+\mathrm{Zn}, \mathrm{Cu}+\mathrm{Ge}$, and $\mathrm{Cu}+\mathrm{Al}$. The stacking fault energy of $\mathrm{Cu}+\mathrm{Ga}$ has not yet been measured; the value of $\mathrm{Ag}$ is about $25 \pm 5 \mathrm{erg} \mathrm{cm}^{-2}$ obtained by extrapolation from measurements on $\mathrm{Ag}+\mathrm{Al}$ and $\mathrm{Ag}+\mathrm{Zn}$ alloys. The values for the copper alloys can be extrapolated to $70 \pm 10 \mathrm{erg}^{-2}$ for pure copper. This value is somewhat higher than previously expected by several authors, 29,30\% but considerably lower than those calculated from stress strain curves by seeger and his school. 31 These values of the stacking fault energy are preferred to those calculated from the analysis of stress strain curve data because of the directness of method and the lack of a large amount of intervening theory which is 
itself not on a sure foundation. Thornton et al. $28 /$ have recently given a critique of these two methods of measuring stacking fault energies.

In Fig. 6 values of the twinning stress, $\sigma_{\mathrm{T}}$ are plotted against the stacking fault energy, $\gamma$, for the copper alloys studied. $3,25,32 /$ The standard errors of the means of the twinning stresses are shown by the inner bars of the vertical lines through the points. The length of these vertical lines is a measure of the standard deviations of the distribution of observations. The data on the three alloy systems all lie on the single theoretical line. The basis for this line and for the lines drawn through the orientation variation plots for silver and copper will be discussed in section 3.2 .

The twinning stress is a statistical variable and although the means of the observations fit on the theoretical line it is possible that some of the variance can be accounted for by variations with temperature and orientation. Fig。 7 shows the variation of the twin stress with an orientation variable, $\theta$. for copper and silver (derived from references 3 and 23). $\theta$ is the ratio of the resolved shear stress for slip to that for twinning at the onset of twinning. Both these sets of data show a considerable variation of the twin stress with orientation, but in opposite senses. The slight increase in 
twin stress in copper between 4.2 and $77.3^{\circ} \mathrm{K}$ observed, but not considered significant by Thornton and Mitchell, could equally well be due to an intrinsic orientation variation. Crystals which have high values of $\theta$ twin at 4.2 but not at $77.3^{\circ} \mathrm{K}$, and these crystals twin at a lower stress. Blewitt et al.17/ had already found this orientation dependence of the occurrence of twinning. The twin stress in copper is so high that at $77.3^{\circ} \mathrm{K}$ crystals which have orientations away from [111] fracture before reaching the twin stress. Similar observations have been presented by Suzuki and Barrett on Ag + Au alloys: as for copper the tensile axis was almost always between [311] and [111] when twinning occurred. Blewitt's recent data on silver shows an orientation variation in the opposite sense to that of copper. The line shows my attempt to explain these results (section 3,2 )。 It is not known why this effect in silver should be so pronounced.

Despite these variations with orientation, the data still shows a large scatter. Blewitt thinks that his silver data also shows a temperature variation. This variation is more apparent when the two crystals of initially the same orientation strained at different temperatures are compared, but one can see from Fig. $7(\mathrm{~b})$ that the $77.3^{\circ} \mathrm{K}$ points tend to lie near the top of the distribution. Similarly the data of suzuki and Barrett shown in Fig. 8 point to the existence of a small 
increase in the twinning stress at $77.3^{\circ} \mathrm{K}$ when compared with $20.4^{\circ} \mathrm{K}$. There are almost enough points on this plot to test statistically whether the $20.4^{\circ} \mathrm{K}$ points can be reasonably assumed to be samples from the $77.3^{\circ} \mathrm{K}$ distribution. The author has used a Chi-square test on this hypothesis with the result that we can be 95 percent confident that the points do not form the same distribution, and that, therefore, the twinning stress does increase with temperature. cramer, $33 /$ however, is reluctant to put much faith in this test when the number of observations falls much below 100; here $n=39$. Another way of seeing the same thing is that, of the 12 cases where crystals of the same orientation had been tested at 20.4 and $77.3^{\circ} \mathrm{K}$, in nine cases the stresses at 77.3 were higher, in one case lower, and in two cases the values of several tests at both temperatures overlapped. The orientation variation, as far as can be ascertained from their published data, is very small.

The temperature and orientation variation for the copper alloys is even less well known than for the pure metals and $\mathrm{Ag}+\mathrm{Au}$. Apart from the limited amount of published data one reason for this is certainly that in order to establish either such variation, the position of the tensile axis when twinning begins, and the operative slip and twin system must be known. In the alloys systems, where a large unknown amount of overshoot occurs, the stresses on the primary and 
conjugate systems are widely different and this uncertainty would swamp any variation which could otherwise be observed. $3 /$ Certainly in order to establish such variation with certainty, large numbers of specimens will have to be observed, and the tensile axis orientations at the onset of twinning will have to be known for each sample.

The present data is inadequate to establish any very definite orientation or temperature variation of the twin stress. The work on the copper alloys is however adequate to show that the twin stress is largely dependent on stacking fault energy. It is primarily in terms of this parameter than an explanation of the twin stress in terms of dislocation models is offered in Sections 2 and 3 . 
2.1 The Geometry of Twinning in f.c.c. Crystals.

Deformation twinning in f.c.c. crystals takes place by shear in <112> directions on [11i] planes. The atomic arrangement

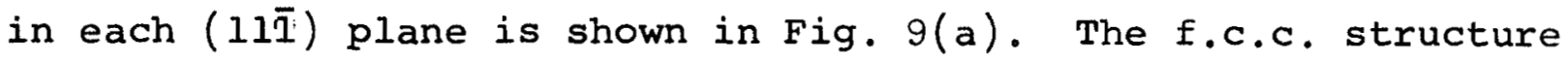
can be characterised by a stacking sequence which describes the relative positions of consecutive close-packed layers in terms of atomic positions at 1,2 or 3 . The stacking sequence for f.c.c. is

$$
\text { ...123123123... }
$$

and for arf.c.c. twin is

$$
\text { . . } 132132132 . .
$$

Three simple types of error in the stacking sequence can occur in f.c.c. crystals. They are:

(1) An intrinsic stacking fault $\quad \ldots 1231 / 31231 .$.

(2) An extrinsic fault $\quad \ldots 123132312 . \ldots$

and (3) A twin boundary ...123121321...

Intrinsic and extrinsic faults 34 may be formed by deformation, when the layers above the plane of the paper in Fig. $9(a)$ are sheared in the directions $\underline{b}_{2}$ and $\underline{b}_{3}$, respectively. A whole dislocation, $\underline{b}_{1}$, is formed from the partial dislocations with Burgers vectors $\underline{b}_{2}$ and $\underline{b}_{3}$, which are joined by a narrow ribbon of stacking fault. $35 /$ 
A twinned portion of the crystal may be built up by producing either intrinsic faults on every close-packed plane, or extrinsic faults on every other plane, leaving partial dislocations in the twin boundary.

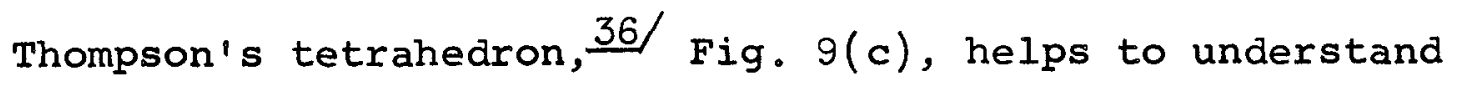
these different methods of producing twins. The whole and partial dislocations which can glide in the twin plane (a) are shown in Fig. 9(b). Using the FS/RH convention for Burgers

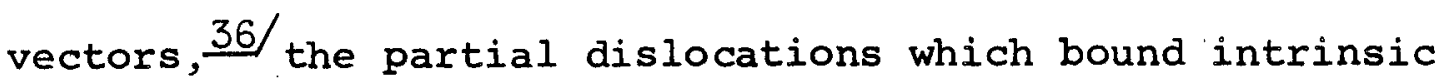
stacking faults on the right-hand side have Burgers vectors of the type $a c$ (i.e., the order of the symbols is Greek-Roman) while those on the left are like $\underline{B Q}$. . Conversely, if we have extrinsic faults, $\underline{\alpha C}$ is on the left and $\underline{B \alpha}$ is the partial dislocation on the right. Under a tensile stress, with the axis in the (100)-(110)-(111) triangle, shaded in Fig. $9(\mathrm{c})$, the dislocations $\underline{\alpha C}$ and $\underline{B \alpha}$ move to the right whereas $\underline{C} \alpha$ and $\underline{\alpha B}$ move to the left. Thus, the sense of the tensile stress is such as to extend intrinsic faults behind $\underline{\alpha C}$ and $\underline{c \alpha}$, and extend extrinsic faults behind $\underline{B \alpha}$ and $\underline{\alpha B}$. The stress on the partial dislocation $\underline{\alpha D}$ is always much lower than on $\underline{\alpha B}$ and $\underline{\alpha C}$ and will not be considered.

Thus, deformation twins produced from intrinsic and extrinsic faults have twinning directions $\underline{\alpha C}$ and $\underline{B \alpha}$, respectively, and shears of magnitude $2^{-\frac{1}{2} \text { and } 8^{\frac{1}{2}} \text {. This can be seen simply: } B Q}=\underline{\alpha C}+\underline{\alpha D}$ 
PAGE 22 IS MISSING. 
therefore, the production of intrinsic faults on every plane, alternately by dislocations $\underline{\alpha C}$ and $\underline{\alpha D}$, is equivalent to producing extrinsic faults by $\beta \alpha$ on every other plane. Whelan $12 /$ has shown that the dislocation interactions present in f.c.c. stainless steel are consistent with there being only one type of fault present; recently, Howie and valdre 37/ have shown that the faults in $\mathrm{Cu}+\mathrm{Al}$ alloys are of the intrinsic type. The twin directions are [Section 1.1], [112] in (11ī) and

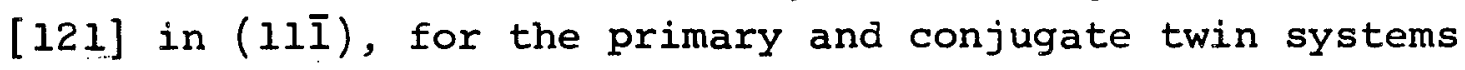
respectively. These directions correspond to partial dislocations $\underline{\alpha C}$ on plane (a) and $\underline{B C}$ on plane (b) respectively, indicating that the twinning is produced by overlapping intrinsic stacking faults. If twins are indeed produced from intrinsic stacking faults then the twinning systems should be different in a compression

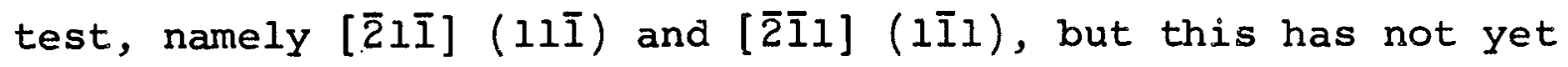
been verified experimentally. 


\subsection{Dislocation Reactions Leading to Twinning}

All the twinning mechanisms so far proposed are "pole" mechanisms, which are discussed by Dr. Westlake in this symposium. The twinning dislocation rotates round its pole, whose component Burgers vector, perpendicular to the twin plane equal to the spacing of these planes. In this way, the sweeping dislocation generates a fault on every plane and so produces an unfaulted final structure. By such a mechanism, a twin can be produced very quickly in the absence of diffusion, and without the need for a separate partial dislocation source on every (1li) plane. Although a pole mechanism seems to be the only reasonable hypothesis when perfect twins are formed, in the case of the lowest stacking fault energy alloys single faults and imperfect twins are also present, which might be produced otherwise. In the authors view, this faulting at low stacking fault energies is to be explained in terms of the relative ease of nucleation and propagation of twins, and not because the concept of a pole mechanism is invalid. This possibility is explored in section 3.3.

The first dislocation mechanism for twinning in f.c.c. was given by cottrell and Bilby. $\frac{38 /}{}$ They considered the dissociation of a length of the dislocation $\underline{A C}$ into the Frank partial $\underline{A \alpha}$ and the twinning dislocation $\underline{\alpha C}$, shown in Fig. 10(a). The dislocation AC forms a "pole" where it leaves the plane (a), and the dislocation $\underline{\alpha C}$ rotates around this pole, returning to meet $\underline{A \alpha}$ 
at the level of either A or B in Fig. $10(\mathrm{~b})$, depending on the sense of the pole dislocation. They considered that the twinning dislocation could go no further as it is obstructed by the dislocation $\underline{A \alpha}$; hence, single layer faults but not twins could be produced in f.c.c. metals. This mechanism has been extended by the present author 39 to account for the production of deformation twins. Having resolved once round the pole the twinning dislocation meets the dislocation $\underline{A Q}$ and recombines to form $\underline{A C}$ again. This whole dislocation can move along its glide cylinder G-G' [Fig $10(\mathrm{c})]$ and redissociate at the next atomic plane, producing the double fault sequence shown in Fig. $10(\mathrm{~d})$. In this way a twin of finite thickness can be built up from a simgle stacking fault. It has the same twinning direction $\alpha c$ or (a) [or $\beta C$ on (b)] as the twins found experimentally. Before discussing in detail the dislocation configuration in this twin cource, I should like to consider the other published mechanisms of deformation twinning ..18,20,40/ These authors consider that the dissociation of a Lomer-Cottrell dislocation, $1,1,42 /$ produces. twinning. Haasen and $\mathrm{King} 2 \mathrm{O} /$ state explicity that they are discussing the Lomer-cottrell dislocation formed by interaction of dislocations of the primary and conjugate glide systems [Fig. 11(a)]. In our notation, this has a Burgers vector $\underline{A B}$ and is normally visualized as in Fig. 11(b). Stroh $43 /$ considers that the Lomer-cottrell aislocation is not a very strong barrier in this configuration and will rearrange so that its apex is away 
from the piled-up group as in Fig. 11(c), where the double lines represent extrinsic stacking faults. The dissociation of this dislocation produces extrinsic faults and a twinning direction $\underline{A B}$ or $\underline{\alpha B}$, which does not agree with the experimental evidence. It is possible that the Lomer-Cottrell barrier looks like Fig. 11(d), but this configuration is thought to have a very low strength as the stair-rod dislocation $\alpha A / B \beta$ has a high energy. 12/ Another objection to the theory 20 comes from the use of arbitrary primary slip dislocations as "poles". In rotating about any pole dislocation, segments of the twinning dislocation meet one plane apart. It does not help to envisage the dislocation rotating about a piled-up group of $\mathrm{n}$ dislocations $20 /$ as this produces faults $n$ : planes apart; to produce faults on every plane the partial dislocations must pass each other one plane apart and this requires a very high stress of about $180 \mathrm{~kg} \cdot \mathrm{mm}^{-2}$.

In the authors opinion, twins and wide stacking faults on the conjugate slip plane are not produced from Lomer-Cottrell dislocations $\underline{A B}$ but from dislocations of the primary slip system BC which lie partly in the conjugate slip plane; and undergo the reaction $\underline{B C} \rightarrow \underline{B B}+\underline{B C}$. Similarly, twins on the primary slip plane are produced by the dissociation of the conjugate slip dislocations $\mathrm{AC}$ as discussed before, namely $\underline{\mathrm{AC}} \rightarrow \underline{\mathrm{A} \alpha}+\underline{\alpha C}$. The mode of operation of such a source will now be considered in more detail.

The stages in the production of a lenticular twin from a single dislocation $A C$ can be followed in Fig. $12(a)$ to (f). $.39 /$ 
Initially, the dislocation lies in plane (a) betwean the nodes $\mathrm{N}_{1}+\mathrm{N}_{2}$, and the poles $\mathrm{X}$ and $\mathrm{Y}$ lie on plane (b). In Fig 12(b), the source dissociates into $\underline{A \alpha}$ and $\underline{\alpha C}$ on (a). When the twinning dislocation is roughly semicircular it is unstable $44 /$ and rapidly reaches the configuration (c). Segments of the twinning dislocation meet along RS one plane apart. Seeger $45 /$ has suggested that these segments could pass each other dynamically, gaining enough momentum as they rotate about $X$ and $Y$ to pass over the potential energy well of the configuration RS. This would mean that the lenticular twin of Fig. 12(f) could be generated without further hindrance. It is not, however, a necessary condition for the formation of the twin. The source dislocation is reformed by the revolution of the partial dislocation $\underline{\alpha C}$; the partials marked "up" and "down" in Fig. 12(c) arrive at the positions marked $A$ and $B$ in Fig. $10(b)$ ' A unit jog travelling along the source from the mode $\mathrm{N}_{2}$ (or $\mathrm{N}_{1}$ ) reforms the source $\mathrm{T}_{2}$ which can then redissociate [Fig. 12(d)] to form another ring of fault. Dislocations $\underline{\alpha C}$, bounding all but the top and bottom layers of a helical twin, annihilate along RS. When these dis-. locations $P_{1}$ and $P_{2}$ [Fig. 12 (e)] at the top and bottom of the twin are sufficiently far apart, they can overcome their mutual attraction and spiral round $Y$ and $X$ respectively. A lenticular twin can thus be built up [Fig. 12(f)] whose thickness is limited by the back-stress and by the length of the pole dislocation. Because there is no long range force between the dislocations $\underline{A \alpha}$ and $\underline{\alpha C}$, it would seem obvious that the most difficult stage in 
twinning is the formation of the configuration: shown in Fig. 12(b). However, if the Frank partial $\underline{A \alpha}$ is itself split into partial: dislocations with smaller Burgers vectors $(e g$. $\underline{A} \underline{6}+\underline{\delta a}$ ) then there will be a short range force preventing the splitting $\underline{A C} \rightarrow \underline{A \alpha}+\underline{\alpha C}$. Therefore, the partial dislocation structure of the source must be studied in detail, to determine the critical stage in twin nucleation.

Hirsch $46 /$ has emphasized that the energy to form a constriction in a slip dislocation may be so high that a jog may itself be split into partial dislocations. The unsplit jog produced, in the conjugate slip dislocation $\underline{A C}$, when it is intersected by dislocations of the primary system BC, is shown in Fig. 13(a). The jog lies along $\mathrm{BC}$, the direction common to the planes

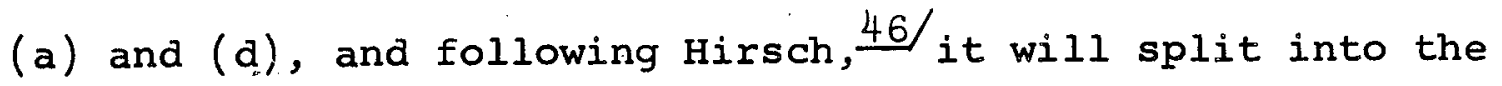
configuration of Fig. 13(b). The jog is thus split into the partials $(\underline{A \delta}+\underline{\delta \alpha})$ and $\underline{\alpha C}$, which is exactly the splitting required for twinning on plane (a). Hirsch considers that these "vacancy" jogs are stable, as the stress tends to separate the partials in the jog. Supposing the pole $Y$ is more effectively pinned than the pole $\mathrm{x}$ in Fig. $13(\mathrm{c})$ by such vacancy jogs, then the length of the twinning dislocation $\alpha \mathrm{c}$ can be increased very easily. When it is long enough, the source can operate as shown in Fig. 13(b) and (c). The analogy of Fig. 12(d) in terms of the partial dislocation structure of the source is shown in Fig. 13(d). 
This investigation of the partial dislocation structure of

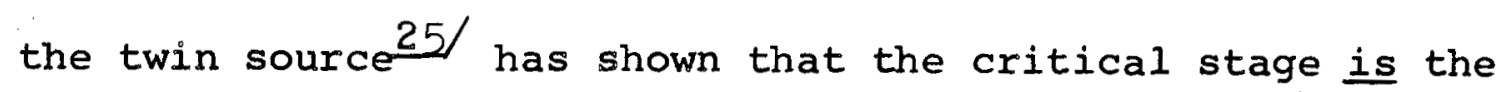
formation of a semicircular loop of fault and that this loop can be nucleated with greatest ease at a "vacancy" jog. The recent observations of the presence in work-hardened copper of dislocation dipoles which are faulted (i.e., have a Burgers vector $\underline{A \alpha}$, $47 /$ add strong support to this description of the twin source. Such a dipole is thought to be formed by the extension of the vacancy jog shown in Fig. 13(b), and would, on further straining, become the twin source shown in Fig. 13(c). The stress-levels at which such a source operates are considered in the next section. 


\subsection{The Work-hardened State}

Since deformation twins in F.C.C. are only produced at high stresses after much work-hardening, the starting point for a discussion of twinning must be the work-hardened state. In discussing the stresses necessary to nucleate a twin it is necessary to know not only the dislocation configuration of the source, but also the local stress field at the twin source; for the simplest calculation shows that some stress concentration is necessary. In order to produce an extended stacking fault behind a partial dislocation of Burgers vector $b_{1}$, a stress $\mathrm{p}$ is required, given by $\mathrm{p}=\gamma / \mathrm{b}_{1^{\prime}}$, where $\gamma$ is the stacking fault energy. For copper with $\gamma=70 \mathrm{erg}^{-2}, \mathrm{p}=47 \mathrm{~kg} \mathrm{~m}^{-2}$, whereas the applied stress for twinning is only $15 \mathrm{~kg} \mathrm{~mm}$. Therefore。 for twinning to occur at all in copper a local stress concentration must exist at the twin source of at least a factor 3 . The form of the stress concentration should be consistent with what is known about the work-hardened state. It is thought to be that caused by a ${ }^{00}$ pile-up" , which consists of an array of dislocations of the same sign on one slip plane. This mechanism of magnifying the stress is used in the next section in an attempt to give a quantitative account of the nucleation and propagation characteristics of deformation twins in $\mathrm{f}_{\circ} \mathrm{C} . \mathrm{C}$. metals and alloys. 


\subsection{Stresses for Twin Nucleation.}

In section 2.2 a dislocation mechanism of deformation twinning was presented. It was shown that the critical stage for the nucleation of twins or large faults is the formation of a semicircular loop of stacking fault. The twinning stress at this critical stage, $\sigma_{T^{\prime}}$ is given by $39 /$

$$
n \sigma_{T}=\gamma / b_{1}+\mu b_{1} / 2 a_{0}
$$

Here $\mathrm{n}$ is the local stress concentration factor, $a_{0}$, the radius of the source, and $\mu$ the shear modulus of the metal.

The dislocation configuration in the neighborhood of the source is shown schematically in Fig. 14(a)。A small pile-up is confined to a length $L$ of the siip plane behind the twin source. The resolved shear stress for slip, $\sigma_{, 0}:$ is sufficient to push the leading dislocation of the pile-up to within a distance, $d$ of the twinning dislocation, which is thereby bent to a radius, $a_{0}$. We assume that the size of the twin source is limited by the distance between forest dislocations crossing the twin plane. If so, the size of the twin source is related to the dislocation density, $N_{\theta}$ by

$$
a_{0}^{2}=3 / 4 N
$$


The distance, $d$, is given in terms of $L$ and $\sigma$ by $48 /$

$$
d=1.84 b^{2} \mu^{2} /\left(2 \pi^{2}(1-v)^{2} L \sigma^{2}\right)
$$

where $b$ is the Burgers vector of a slip dislocation and $y$ is Poisson's ratio. For small distances, $d$, the stress concentration is due to the presence of the first dislocation and is given by

$$
\mathrm{n}_{\mathrm{T}}=\sigma_{\mathrm{T}}+\mathrm{K} \sigma^{2}
$$

with

$$
K=(1-v) L /(1.84 \mu b)
$$

Experimentally it has been found $49.50 /$ that the stress $\sigma$ is related to the dislocation density by

$$
\sigma=0.5 \beta \mu b \mathrm{~N}^{1 / 2}
$$

with $\beta$ approximately unity. Combining expressions (3.1) through (3.6), and writing $\sigma=\theta \sigma_{\mathbf{T}}$, we have

$$
\left[(1-2 \theta / 3 \beta)+K \theta^{2} \sigma_{T}\right] \sigma_{T}=\gamma / \mathrm{b}_{1}
$$

This is an expression for the twinning stress, $\sigma_{T^{\prime}}$ in terms of $K, \theta, \beta$ and $\gamma_{0}^{!}$of these only $K$ is unknown: if the value is chosen so that the value of $\sigma_{T}$ is reproduced for copper. 
then the values of $\sigma_{T}$ for all the copper alloys studied fit into a single line given by equation (3.7). The line is shown for $\beta=\theta=1$ with the experimental values, in Fig. 6 and is seen that the fit of theory to experiment is more than adequate. The value of $\mathrm{L}$ obtained from equation (3.5) is $1350 \AA$. This should be equated, not with the slip line length, $51 /$ but with an effective length over which the dislocations can move freely. In this way the stress concentration may be thought of as the stress from a long pile-up whose long range stress field is very nearly completely relaxed. The constancy of $L$ with increasing stress is a feature of the work-hardening theory of Friedel. 52/

If it assumed that the length $L$ is not constant, but varies with stress, then the fit with experiment is not nearly as good. In particular if the length $L$ is assumed to decrease with stress, $51 /$ but the variation of $a_{0}$ with $\sigma$ is the same, the $\sigma_{T}$ versus $\gamma$ curve is a straight line through the origin in disagreement with experiment. Only if $\mathrm{n}$ and $a_{0}$ are both constant throughout the range of alloys is a tolerable fit obtained. Values for $\mathrm{n}$ and $\mathrm{a}_{\circ}$ have been given by Thornton and Mitchell.3/ However, the more recent measurements of the faulting stresses in the low stacking fault energy alloys 25 suggest that an equation such as (3.7) is more reasonable. 
Equation (3.7) can also be used to investigate the variation of $\sigma_{\mathrm{T}}$ with the variables $\theta$ and $\beta$. As mentioned in Section 1.3, $\theta$ can be obtained from stress strain curves if the slip systems are known. It is a measure of the variation of $\sigma_{\mathrm{T}}$ with orientation, $\theta$ being high for tensile axis near [100] and low near [111]. Assuming that $K$ and $\beta$ are constant. the variation of $\sigma_{T}$ for copper and silver with $\theta$ is shown by the lines on Fig. $7(a)$ and (b). It can be seen that the line follows the data for copper but not for silver. Equation (3.6) relating the stress, $\sigma$, to the dislocation density, $N$, of course rests on sparse experimental evidence, in particular it is not known whether $\mathrm{N}$ varies with orientation at constant $\sigma$. If it did, the first term in Equation (3.7) would have a different dependence on $\theta$, which would be especially noticeable at low stresses when the second term is small. The orientation variation of the twinning stress for copper shows that the stress concentration is maintained by the resolved shear stress for slip, $\sigma$, and the amount of variation with $\theta$ is a measure of the stress concentration necessary to produce twinning. It would be particularly helpful to do more experiments to tis determinecthenextentcof such orientationvariations atiss.

The variations in twin stress with temperature could come about from variations in $k$ or $\beta$ in equation (3.7). since $K$ is connected with the elastic interactions of dislocations 
it is thought that this will only vary with temperature through the shear modulus, i。e, at most $10 \%$ between 0 at $273^{\circ} \mathrm{K}$. However, the experiments which found that part of the flow

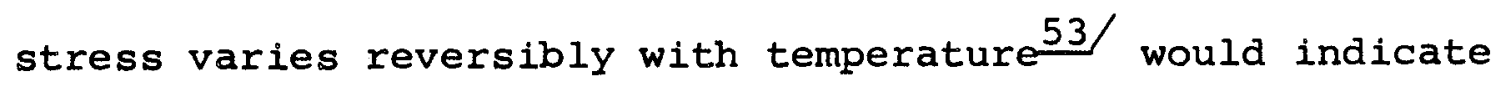
that $\beta$ does vary, increasing at low temperatures. From equation $(3,7)$ this means that $\sigma_{T}$ is reduced at low temperatures especially when the stress is already low. This may account for the probable occurrence of a temperature dependence in silver and $\mathrm{Ag}+\mathrm{Au}$, and also that there is a much smaller effect in copper. 


\subsection{The Propagation of Deformation Twins.}

One of the most striking characteristics of the low stacking fault energy alloys is that they twin profusely on a fine scale, although the deformation does not proceed by a Lllders band, and the stress strain curves are smooth. In the authors view, this with other electron microscope evidence indicates that there is a transition in behavior from the high $\gamma$ alloys in which the nucleation is critical to the low $\gamma$ alloys in which the nucleation of faults is easy, whereas, propagation of twins through the forest of dislocations is difficult. In this case the twins grow slowly by breaking down interactions with the forest dislocations and do not exhibit the catastrophic behavior of the materials with high stacking fault energy. This transition also occurs on decreasing the testing temperature in certain alloys with a critical stacking fault energy. In this section, a model for the propagation of a deformation twin is formulated and the effect of forest interactions in resisting twin growth is analysed. The model is tentative but does account for the behavior which as been described above.

Eshelby 24/ has given expressions for the energy of an ellipsoidal inclusion embedded in a matrix: It is easy to show that an ideal example of such an inclusion is a deformation twin. The similarity of a deformation twin and a circular pile-up of dislocations 54 means that the profille of a twin near its tip is 
a parabola: and that, therefore, the whole twin will be in the form of an ellipscid. The total energy increase caused by inserting such an ellipsoid in the matrix can be written

$$
E=E_{I}+E_{L}+E_{S}+E_{R}
$$

where $\mathrm{E}_{I}$ is the work done by the applied stress and $\mathrm{E}_{\mathrm{L}}$ is elastic energy caused by the presence of the ellipsoid. $E_{S}$ is the surface energy and $E_{R}$ the resistive energy caused by propagating the twin through the dislocation forest. For a twin in the shape of an oblate spheroid, with a and $c$ the major and minor radii, the various terms are given by

$$
\begin{aligned}
& \mathrm{E}_{I}=-8 \pi n \sigma_{\mathrm{T}} \epsilon \mathrm{ca} \mathrm{a}^{2} / 3, \\
& E_{L}=2 \pi^{2}(2-v) \mu \epsilon^{2} c^{2} \mathrm{a} / 3(1-v),
\end{aligned}
$$

and

$$
E_{s}=m \gamma a^{2}
$$

Here, $n$ is the stress concentration factor, and $\epsilon$ is the nonzero component of the strain tensor in the twin: for both $f . c . c$. and b.c.c. twins $\epsilon$ has the value $8^{-\frac{1}{2}}$. We are also assuming that the twin boundary energy is just half the stacking fault energy: $29 /$ the recent evidence $55 /$ suggests that it is less than this, but this only strengthens the argument of this section. From Eqs. (3.8) to (3.11) it can be seen that, if $E_{R}$ does not depend on $c$, there is a value of $(c / a)$ for which $E$ is minimum, 
and which is the equilibrium profile of the propagating twin. This value is, with $v=1 / 3$,

$$
c / a=4 n \sigma_{T} / 5 \pi \mu \epsilon
$$

This is in exactly the same range as the $d / a$ ratios observed (Section 1.2). With this value of $(c / a), E_{I}=-2 E_{L}$, and, therefore, the Eq. $(3,8)$ can be written

$$
E=-16 n^{2} \sigma_{T}^{2} a^{3} / 154+\pi \gamma a^{2}+E_{R}
$$

Whether a twin will propagate or not depends on whether $\mathrm{dE} / \mathrm{da}$ is negative or positive, respectively. This will depend on the detailed behavior of $n$ and of $E_{R}$ as a function of a. For $\mathrm{n}$ we take

$$
\mathrm{n}=1+(\mathrm{L} / \mathrm{a})^{\frac{1}{2}}
$$

which is the value appropriate to a pile-up of dislocations when $a$ is a moderate distance from the head of the pile-up. The value of $\mathrm{I}$ used will be that obtained from nucleating. $\mathrm{E}_{\mathrm{R}}$ will be estimated in the next paragraph. In passing, it may be pointed out that, on the nucleation theory based on the existence of embryos (for example $e^{56 /}$ ), $d E / d a=0$ is the condition for nucleation. "With $a_{0}$ given by $(3.2)$ and $(3.6)$ and $E_{R}=0$. This 
gives

$$
15 \pi \gamma \mu=8 \sigma_{\mathrm{T}}^{2} \mathrm{a}_{\mathrm{O}}\left[3+5\left(\mathrm{~L} / \mathrm{a}_{\mathrm{O}}\right)^{\frac{1}{2}}+2\left(\mathrm{~L} / \mathrm{a}_{\mathrm{O}}\right)\right] .
$$

This equation gives values of $\sigma_{\mathrm{T}}$ very similar to Eq. (3.7) and the values given by $(3.15)$ will be used to simplify the presentation of the ideas in this section. It is not intended to convey the idea that the twin nucleus forms as an ellipsoid. For $a<a_{0}$ the ellipsoid has positive energy and cannot form athermally. This, of course, is not true when the nucleus is formed from existing dislocations.

The dislocation resistance, $E_{R}$, may be calculated as follows. We assume that the interaction responsible for stopping the twins is the one shown in Fig. 14b. It is the reverse of the reaction leading to twinning, namely a twinning dislocation $\underline{\alpha C}$, plus a slip dislocation $\underline{C A}$ forming a Frank partial $\underline{a A}$. The dislocations $\underline{C A}$ lie on planes (b) and (d) and hence can form parallelograms of interactions in the twin plane. The stress required to break up these interactions, $p_{0}$ has been calculated by saada 57 for the case of two dislocations which form Lomer-Cottrell dislocations. This is similar to the case considered bere and it can be estimated that his equations should apply quite well。 He finds, in our notation, for the case of two dislocations, $b_{1}$, that

$$
p=\alpha \mu b_{1} N^{\frac{1}{2}}
$$


where $\alpha$ can vary between 0 and 2 and is on average about 0.4 . The resistive force on each loop of twinning dislocation, of radius $r$, which is stopped by these forest interactions is therefore $2 \pi \mathrm{rpb}_{1}$. If we imagine that all the forest dislocations lie on such loops, spaced at a distance $N^{-\frac{1}{2}}$, then the density of loops per unit radius is $\mathrm{N}^{\frac{1}{2}}$. The total resistive force, $\sigma_{R}$, due to the dislocations is thus

$$
d E_{R} / d a=\sigma_{R}=\int_{0}^{a} 2 \pi r p b_{1} N^{\frac{1}{2}} d r=\alpha \mu b_{1}^{2} \pi a^{2} N
$$

When the twin meets the dislocations ( $d \mathbb{E} / d a$ ) must be less than zero if the twins are to propagate freely. For a value of $a=t a$ and $\beta=\theta=1$, the Eq. $(3.13)$ can be written, incorporating the results of Eqs. $(3.15)$ and $(3.17)$ as

$$
\begin{aligned}
\mathrm{dE} / \mathrm{da}= & -0.6 \mu \mathrm{b}^{2} t^{2}\left[\left(1-t^{-2}-1.4 \alpha\right)\right. \\
& +1.67(\mathrm{~L} / \mathrm{a})^{\frac{1}{2}}\left(1-t^{-3 / 2}\right) \\
& \left.+0.67(\mathrm{~L} / \mathrm{a})\left(1-t^{-1}\right)\right]
\end{aligned}
$$

The Eq. (3.18) represents the force trying to propagate the twin. It is important to bear in mind the limits of applicability of this equation. When $t=1$, the twin nucleates, and the value of $\alpha$ is zero, as the twin is not in contact with any forest dislocations. The twin first hits the forest dislocations at values of $t$ somewhat greater than 2 . If $d E / d a$ is negative for all small values of $t$ then the twin interface will move very. fast 
and there will never be time for the interactions, which give rise to the resistance, to form. Thus, for large a, and for fast moving twins, $\alpha$ can be much smaller than its static value. The important process on this model then is that the twins either are, or are not, stopped by the dislocation resistance at small values of $t$, of the order of 2 to 4 . The transition in behavior (from twins which can propagate to those which cannot) is observed experimentally in $\mathrm{Cu}+20$ percent $\mathrm{Zn}$ and $\mathrm{Cu}+7$ percent $\mathrm{Al}$ at a stress of about $7 \mathrm{~kg} \cdot \mathrm{mm}^{-2}$. This corresponds to $\mathrm{a}_{0}=650 \AA$ 。 If this transition is used to determine the value of $\alpha$, a value of about 1.5 is obtained for $t=3 \%$. This is higher than the value calculated by saada 57 but is still in the possible range. If we use Eq. $(3.18)$ to determine the propagation characteristics of copper, with $a_{0}=300 \AA$, $/$ da is less than zero until $t=10$. By this stage the twin will be moving fast and $\alpha$ will be less than 1.5. Thus, twins in copper will not be stopped by the dislocations. The high value of a will explain why the twins are stable when the stress is removed. It will also explain why the low stacking fault energy alloys never show serrations on the stress-strain curve. If $1.4 \alpha$ were less than unity, one would expect fluctuations in the stress concentration and source length occasionally to produce twins which propagate throughout the crystal. Since this never happens, we may deduce that the dislocation resistance is sufficient to halt twins whatever their size. The catastrophic effect at high stacking fault energies is then a consequence of the decreased dislocation resistance 
experienced by the twin when it moves quickly through the matrix。

If $\alpha$ does not vary with temperature, then the lack of catastrophic behavior in the alloys of critical stacking fault energy at low temperatures can be explained by an increase in the source length $a_{0}$ at the low temperatures, as discussed in section 3.2. The various types of twin propagation described by Suzuki and Barrett 18 / seem to the author to be a sequence in which the nucleation of twins becomes easier relative to propagation, as the testing temperature is lowered or the silver content of the Ag + Aid alloys is increased.

In this section, a model for the propagation of twins has been presented and explanations have been offered for the characteristic twinning behavior of alloys with high and low stacking fault energies. The presentation is not intended to be final; but it is hoped that it will convince other workers that there are many interesting phenomena in the field of deformation twinning and that some of them, at least, are within sight of a satisfactory explanation. 


\section{Conclusion}

To summarize this paper, I would like to give the impression that, while much has been done on the subject of deformation twinning in $f \circ c . c$. metals and alloys, there is still a lot to do! Although there have been many reports of work on deformation twinning, much of it has been done as a sideline to work on workhardening. It would be invaluable to do some concentrated experimental work in which the twin stress is investigated as a function of temperature, orientation, stacking fault energy and perhaps strain rate. Although the twin stress shows a large scatter, it is possible that a large part of the variance could be associated with these variables. As yet, there are no experiments which show these variations with temperature and orientation in any definite manner, simply because the number of specimens tested has been too small.

There is plenty of scope for electron microscopic observation of deformation twins... It would be particularly interesting to try to obtain definite evidence about the dislocation mechanism of twin nucleation. The present observations are consistent with the mechanism proposed in section 2, but do not show that the hypothesis is necessarily correct.

On the theoretical side, the problems are numerous. If the dislocation mechanism leading to the formation of twins presented in section 2 is accepted, there remains the problem of calculating the nucleating and propagating characteristics of twins, as has 
been attempted in section 3. This last section of this paper is the first attempt in this direction. It is possible that, if the problems presented can be formulated in a more realistic way, the study of deformation twinning will some day become formally integrated with the study of work-hardening, which both have their springs in the theory of dislocations.

\section{ACKNOWLEDGMENTS}

The author is very grateful to Drs. T.H. Blewitt and A. H. King who kindly supplied unpublished data for this review. He also wishes to thank Professor J.S. Koehler for encouragement, and support through the AEC contract 1198 (K). 


\section{REFERENCES}

1. C.H.Mathewson and A. Philip., Trans.A.I.M.E. $\underline{54}, 608$ (1916)。

2. C。H.Mathewson, Trans. A.I.M.E。 78,7 (1928).

3. R. R。Thornton and T。E。Mitchell, Phil。Mag。 I, 361 (1962)

4. C.H. Samans, J.Inst, Metals 55, 209 (1934)。

5. T. A.Wilson, Gen,Elec,Rev。 31,612 (1928)。

6. J.E。Burke and C。S。Barrett, Trans。A.I.M.E。 175 。 106 (1948)。

7. B。E. Warren and E。 P.Warekois,Acta Met。 3. $_{4} 473$ (1955)。

8. M.S.Paterson, J。Appl. Phys。23, 805 (1952) .

9. J.Méring, Acta Cryst。ㄹ. 371 (1949).

10. C.N.J.Wagner, Acta Met。

11. H. M. Tomlinson, Phil。Mag. 3, 867 (1958)。

12. M. J。 Whelan, Proc。Roy, Soc。 (London) A249, 114 (1958).

13. E。Votava, Acta Met。 8,901 (1960).

14. P。R. Swann and J. Nutting, JoInst。 Metals 90, 133 (1961)。

15. J.A. Venables, Proc:Eur.Reg. Conf。 on Electron Microscopy 1, 443 (1960)。

16. J.A. Venables, Proc. 5th International Congress on Electron Microscopy 1. J8 (1962)。

17. T。H。Blewitt, R。R。 Coltman, and J。K.Redman, J.Appl。 Phys。 28, 651 (1957)。

18. H。Suzuki and C。S。Barrett, Acta Met。 $\underline{6}, 156$ (1958).

19: P。Haasen, Phil。Mag。 3, 384 (1958)。 
20. P. Haasen and A. King, Z. Metallk。 51, 722 (1960).

21. Z.S.Basinski, Proc。Roy.Soc. (London) A240, 229 (1957).

22. F。A. Sherrill, M。C.Wittels, and T.H.Blewitt, J.Appl. Phys. 28, 526 (1957).

23. T. H. Blewitt, private communication.

24. J。D。Eshelby, Proc。Roy,Soc。(London) A241, 376 (1957)。

25. J。A. Venables, Ph.D. dissertation, University of Cambridge, England, 1961.

26. A. Howie and P. R。 Swanni, Phil。Mag。 6,1215 (1961)。

27.R.Siems, P。Delavignette, and S。Amelinckx, Z。Physik 165. $502(1961)$ 。

28. P.R. Thornton, T。E. Mitchell, and P。B。Hirsch, Phil。 Mag. I. 1349 (1962)。

29. R。Fullman。 J。Appl。Phys. 22。 448 (1951)。

30. P. R. Thornton and P. B.Hirsch, Phil. Mag。 $\underline{3}_{0} 738$ (1958).

31. A. Seeger, R。Berner, and H。Wolf。Z。Physik 155, 247 (1959)。

32. A. H。 King, private communication.

33. H. Cramér, Mathematical Methods of statistics (Princeton University Press, 1946)。

34. F。C.Frank, Phil。Mag。 42.809 (1951)。

35. R。 D. Heidenreich and W. Shockley, Conference Report on the strength of Solids, (London, Physical society, 1948), p. 57 .

36. N. Thompson, Proc. Phys. Soc. (London) B66, 481 (1953).

37. A. Howie and V. Valdré, private communication. 
38. A. H. Cottrell and B. A. Bilby, Phil. Mag. 42, 573 (1951).

39. J.A.Venables, Phil。Mag。 6379 (1961)。

40. A. Ookawa, J.Phys.Soc。 Japan 12, 825 (1957).

41.W.M. Lower, Phil。Mag。42。1327 (1951)。

42. A.H.Cottrell, Phil。Mag。 43.645 (1952)。

43. A. N. Stroh, Phil。Mag。1。 489 (1956)。

44. F。C.Frank and W。T.Read, Phys。Rev。 79, 722 (1950).

45. A. Seeger, Z。Metallk。47, 653 (1956).

46. P。B。Hirsch, Phil。Mag。․63, (1962)。

47. J。Steeds and P.B.Hirsch。 private communication。

48. J。D。Eshelby, F。C.Frank, and F。R。N。Nabarro, Phil。 Mag。ㄴ․ 351 (1951)。

49. J.A. Venables, Phil。 Mag。 7., 1969 (1962)。

50. J.E. Bailey, to be published。

51. A. Seeger, J。Diehl。S.Mader, and HoRebstock, Phil。 Mag. 2. 323 (1957)。

52. J.Friedel,Phil。Mag。46, 1169 (1955)。

53. A. H. Cottrell and R. J.Stokes, Proc。Roy.Soc。 (London) A233. 17 (1955).

54. G。Leibfried, $\mathrm{Z}$ 。 angew。Physik 6251 (1954)。

55. M。C.Inman and A.R。Khan, Phil。Mag。․․ 937 (1961)。

56. H. Knapp and $U_{j}$ o Dehlinger。Acta Met。ㄴ. 289 (1956)。

57. G. Saada,Acta Met。 8.841 (1960)。 


\section{FIGURE CAPTIONS}

Fig. 1(a). A cluster of fine twins in a $\mathrm{Cu}+8.9$ at. percent $\mathrm{Al}$ alloy strained to $26 \mathrm{~kg} \cdot \mathrm{mm}^{-2}$ at $77.3^{\circ} \mathrm{K}$.

(b). Selected area diffraction pattern from the area (a), showing twin and matrix (110) lattices.15/

Fig. 2(a). The growth of a Lllders band of twin in copper at $4.2^{\circ} \mathrm{K} .17 /$

(b). Electron micrograph of individual twins in a Lliders band in copper at $4.2^{\circ} \mathrm{K}$. $16 /$

Fig. 3(a)。 Types of twin propagation in Ag + Au alloys.

(b). Stress-strain curves for $\mathrm{Ag}+25$ percent $\mathrm{Au}$ alloy. $18 /$

Fig. 4. Faults and twins in $\mathrm{Cu}+8.9$ at. percent $\mathrm{Al} .25$

(a). Faults on the primary and conjugate slip planes at $A$. $\sigma_{\mathbf{T}}=5.5 \mathrm{~kg} \cdot \mathrm{mm}^{-2}$.

(b). Twins on the conjugate slip plane stopped by dislocations. $\sigma_{\mathbf{T}}=7.3 \mathrm{~kg} \cdot \mathrm{mm}^{-2}$.

(c). Twins on the conjugate and critical slip planes. $\sigma_{\mathrm{T}}=9.0 \mathrm{~kg} \cdot \mathrm{mm}^{-2}$.

Fig. 5. Stacking fault energies of $\mathrm{Cu}+\mathrm{Zn}, \mathrm{Cu}+\mathrm{Al}$ and $\mathrm{Cu}+\mathrm{Ge}$ alloys as a function of the electron to atom ratio e/a.28/

Fig. 6. Twin stress versus stacking fault energy for copper

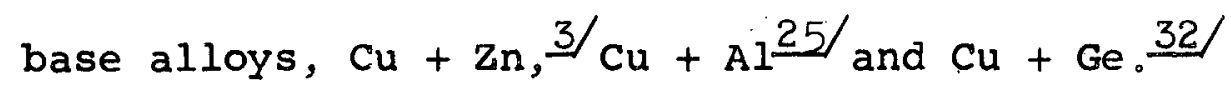


Fig. 7. The variation of twin stress with orientation for copper and silver. The parameter $\theta$ is the ratio of the resolved shear stresses for slip and twinning at the onset of twinning.

Fig. 8. The temperature dependence of the twinning stress for silver-gold alloys $18 /$.

Fig. $9(a)$. Atomic arrangement in a [111\} plane of a f.c.c. lattice.

(b). Dislocations which are glissile in plane (a).

(c): Thompson's tetrahedron, and its orientation relative to the tensile axes in the hatched triangle 100-110-111。

Fig. 10. Cottrell and Bilbys twinning mechanism and its extension. $39 /$

Fig. 11. Configurations of Lomer-Cottrell dislocations.

Fig. 12. The production of a twin from a twin source. $39 /$ See text for discussion,

Fig. 13. The operation of an extended vacancy jog as a twin source. See text.

Fig. 14(a). Schematic drawing of the dislocation distribution near the twin source. The dislocations $\underline{B C}$ form a small pile-up of length $\mathrm{L}$. The plus and minus signs indicate forest dislocations crossing the twin plane.

(b). The forest dislocation interaction with the twin dislocation $\alpha c$, which is thought to be responsible for stopping the propagation of twins. 


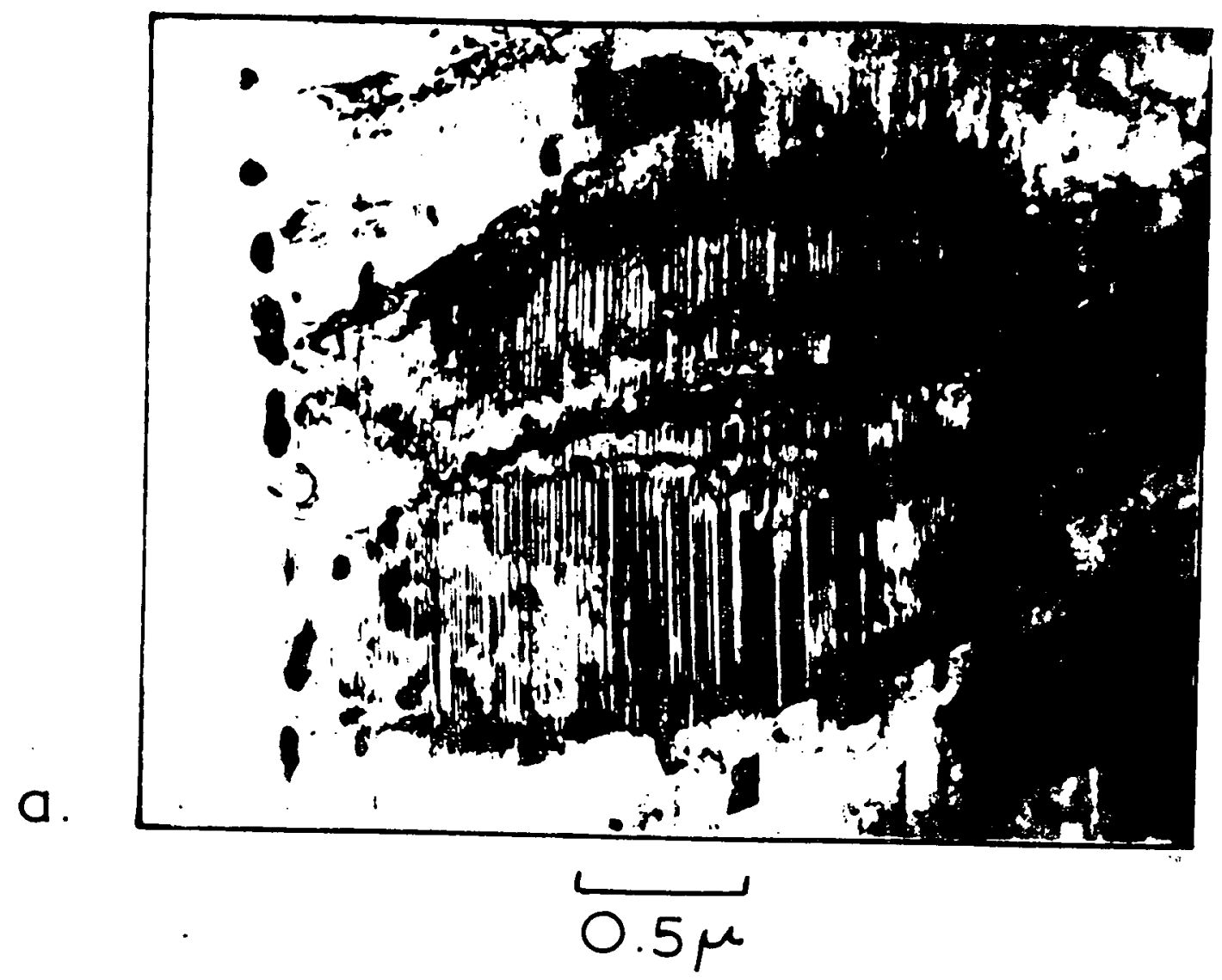

b.

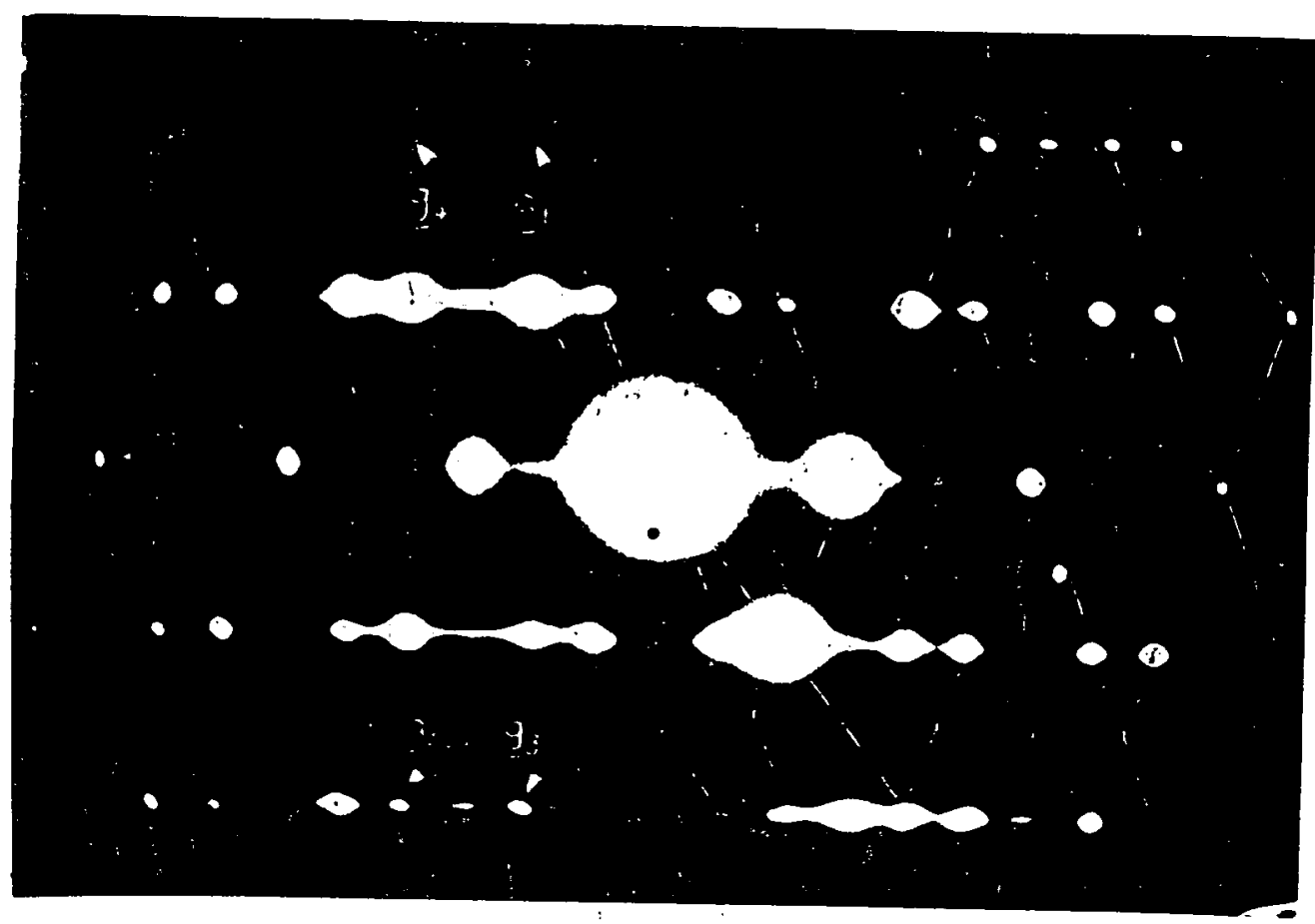



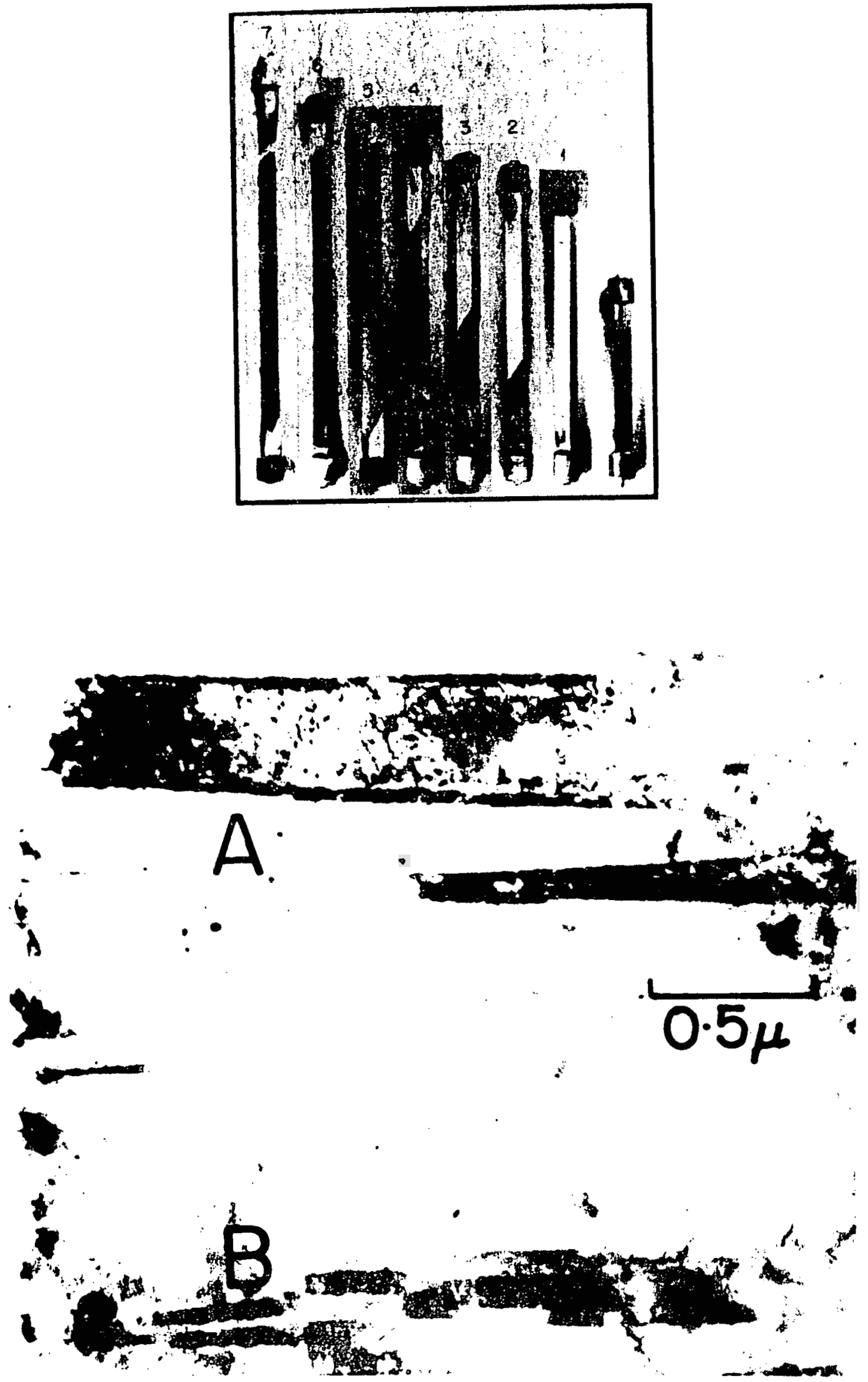

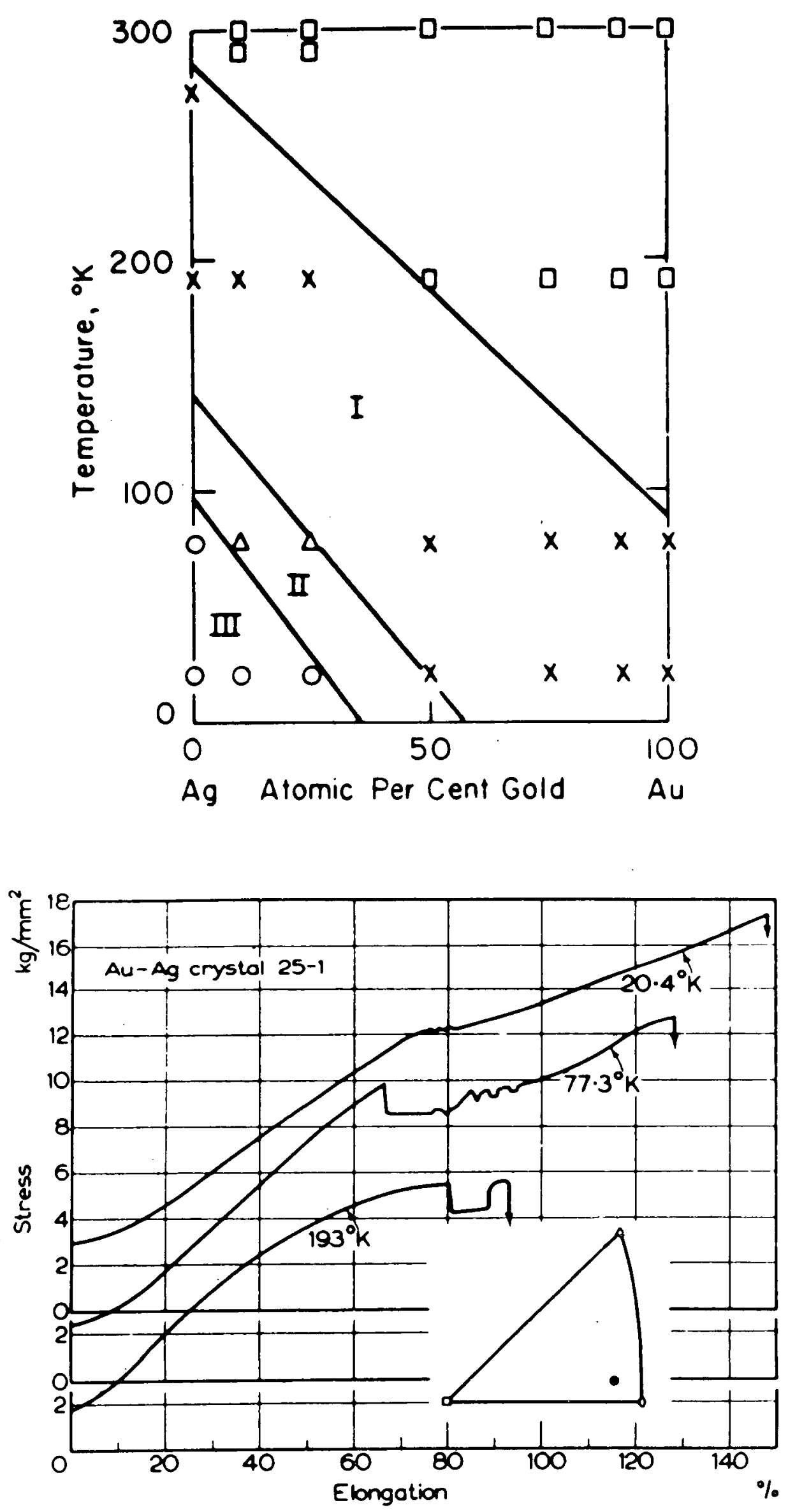

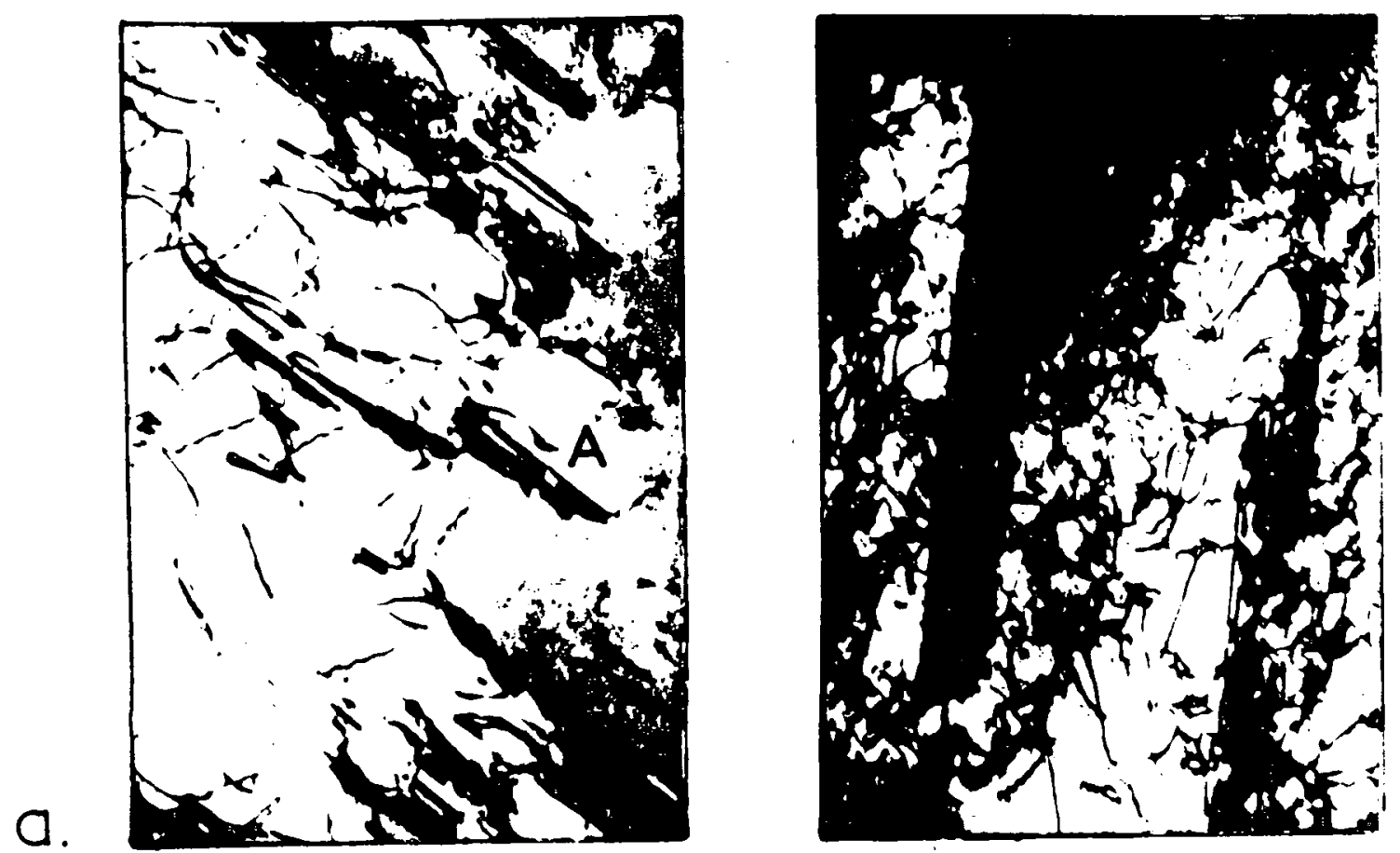

$0.5 \mu$

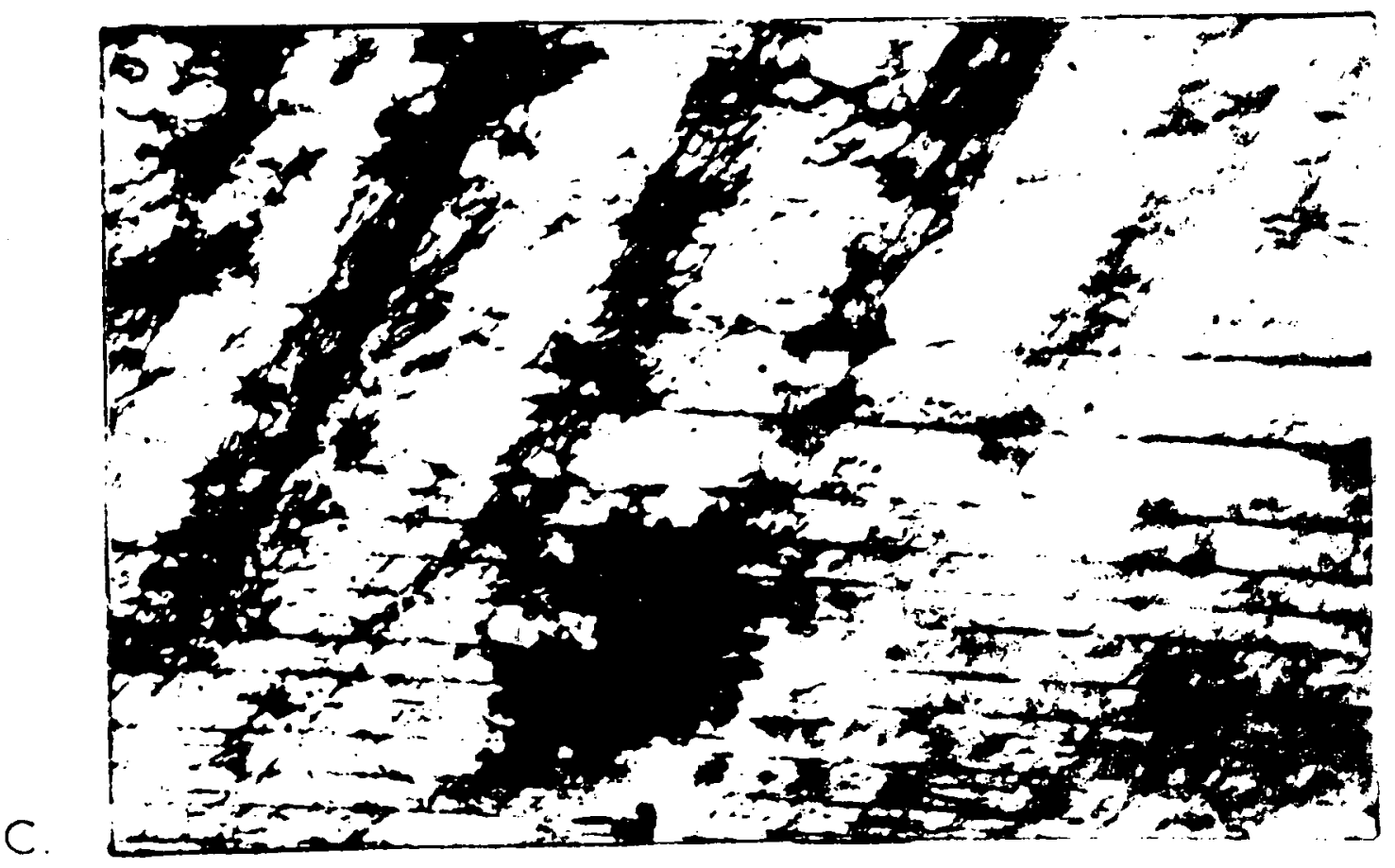




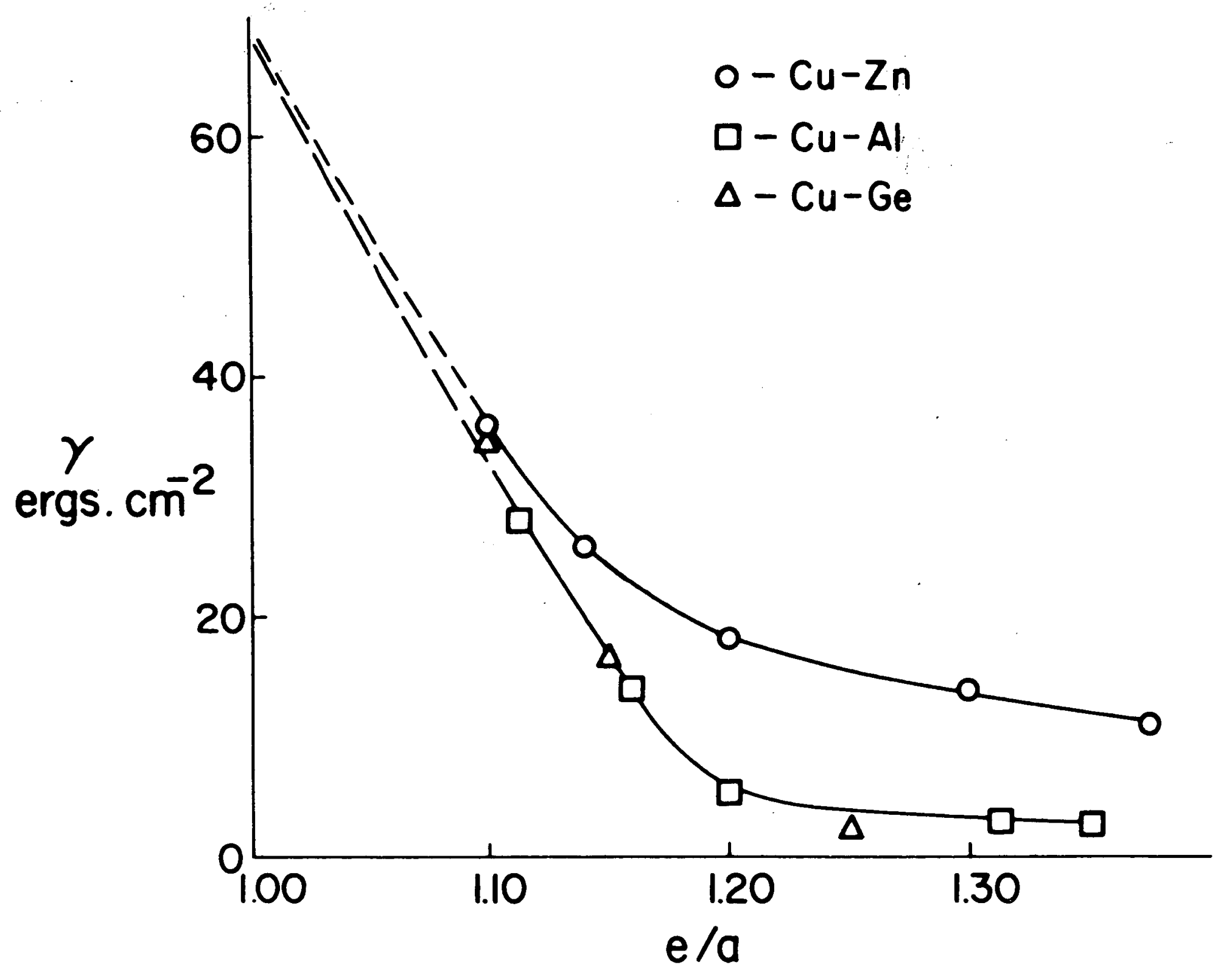




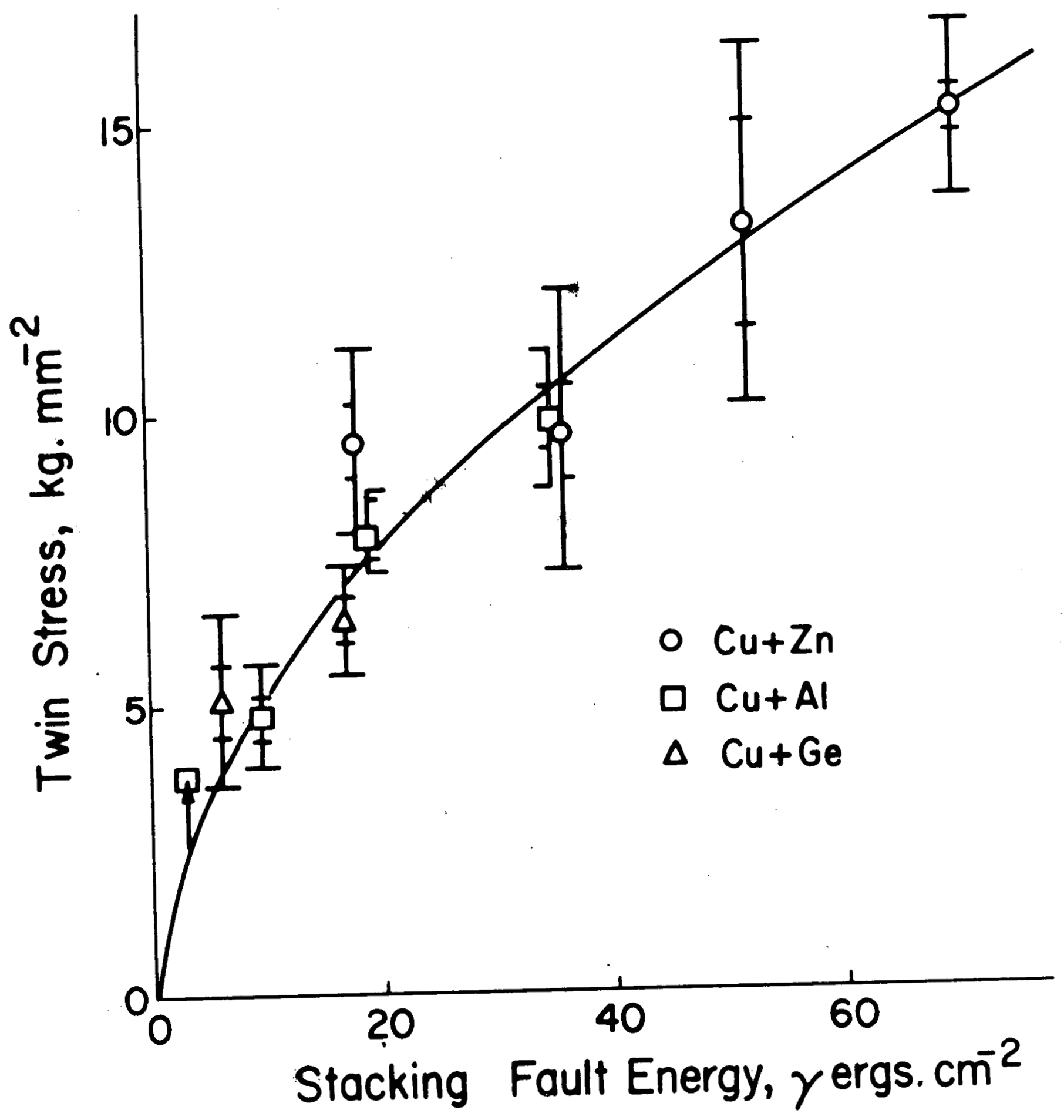




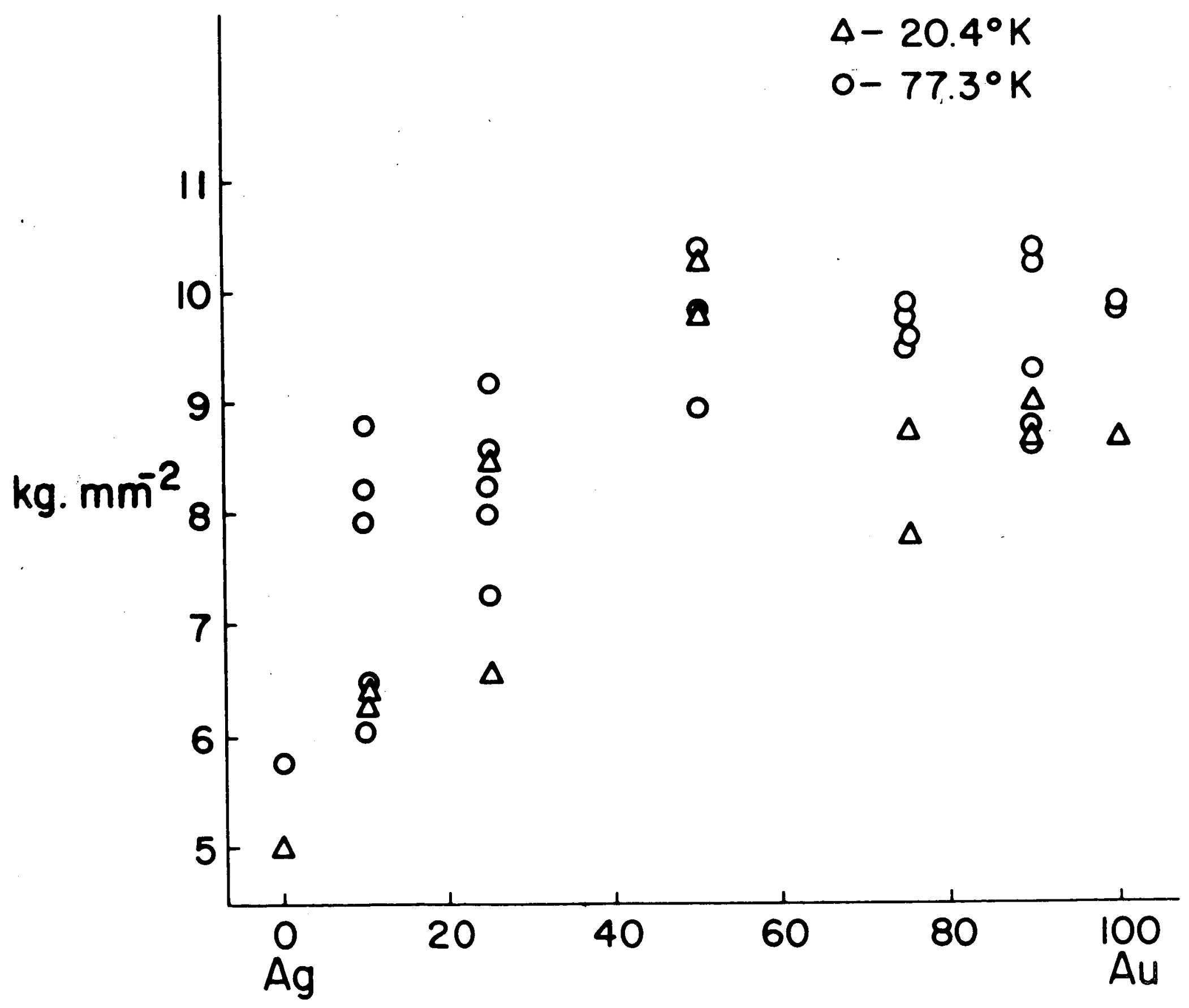



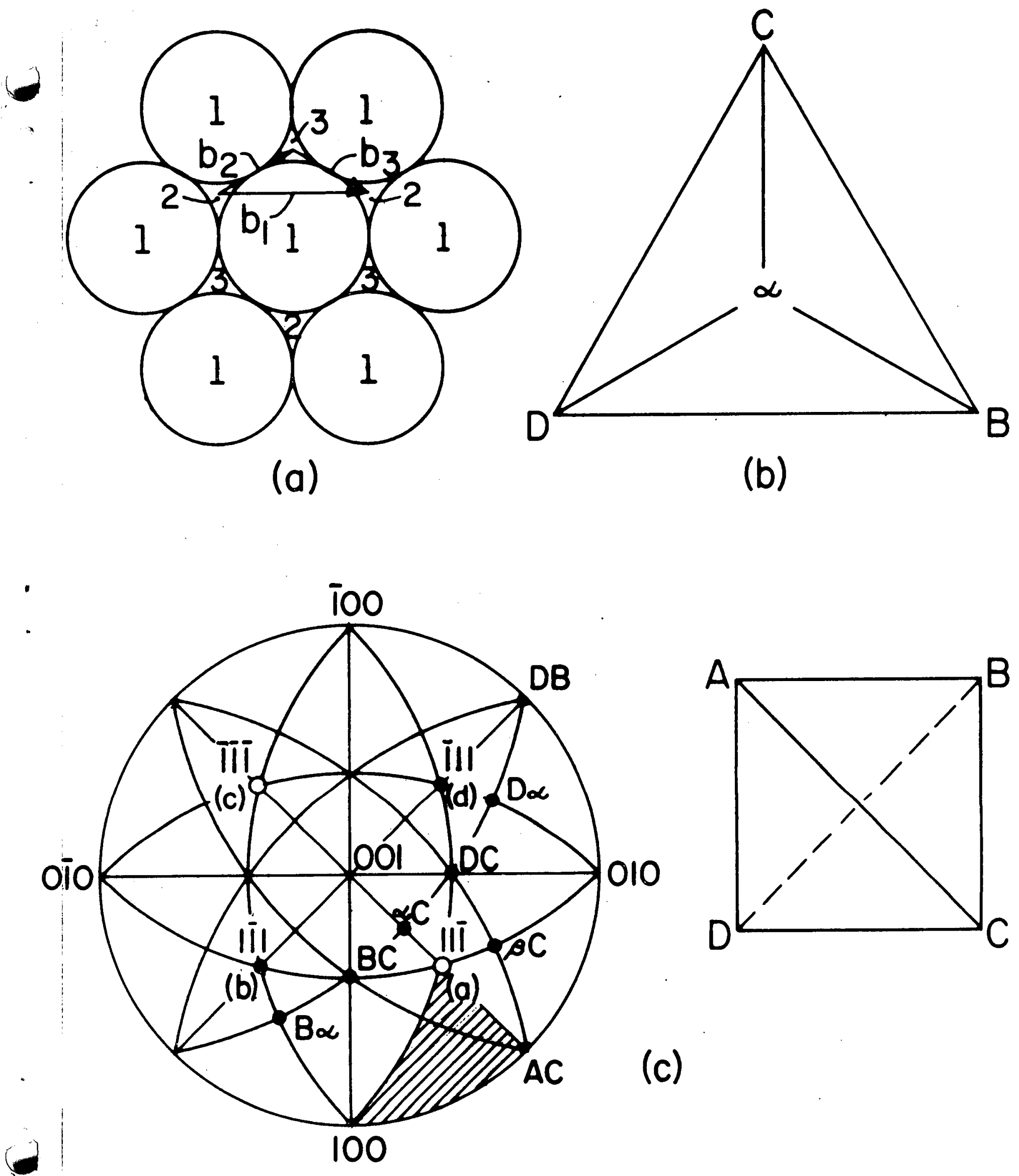


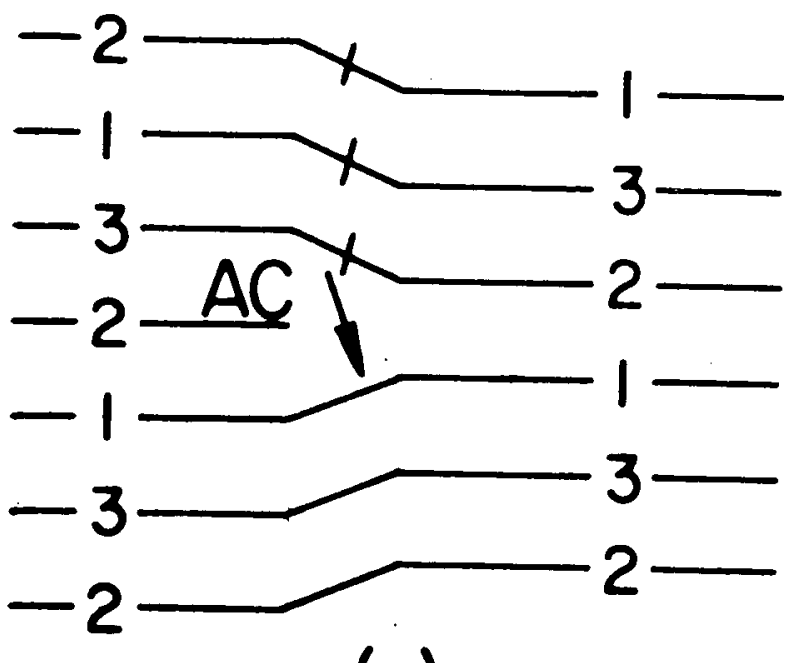

(a)

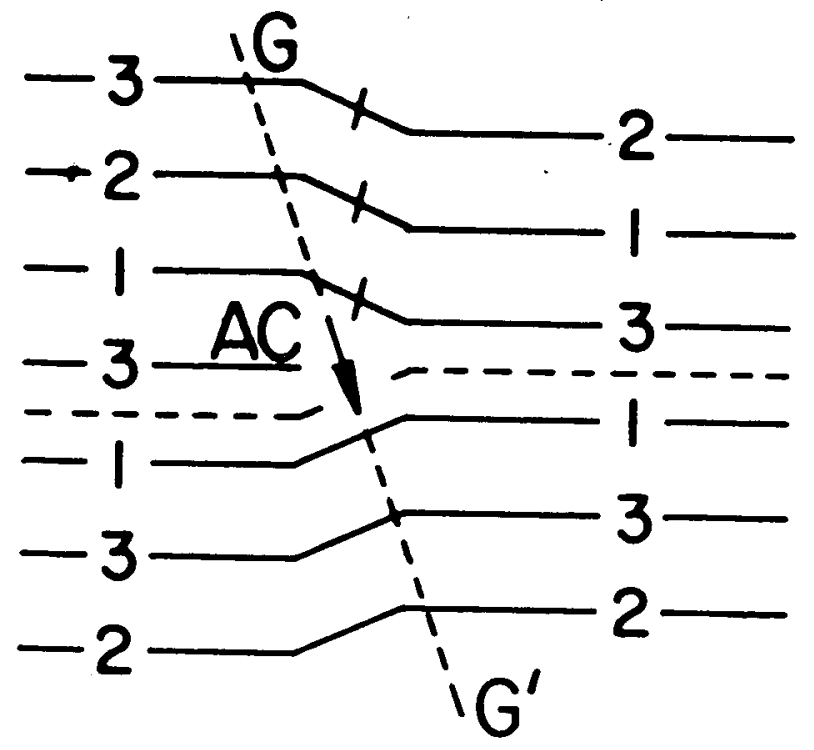

(c)

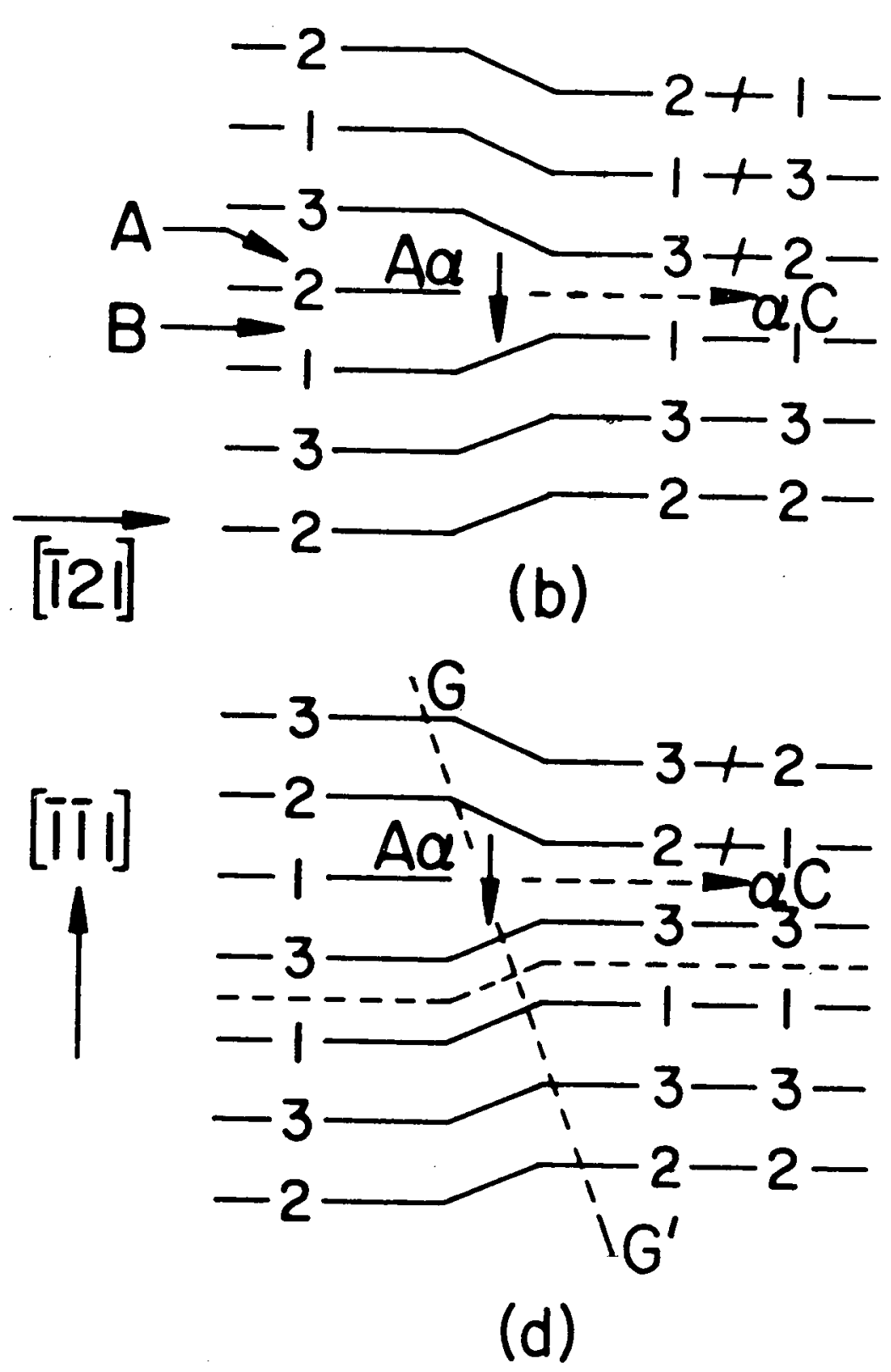



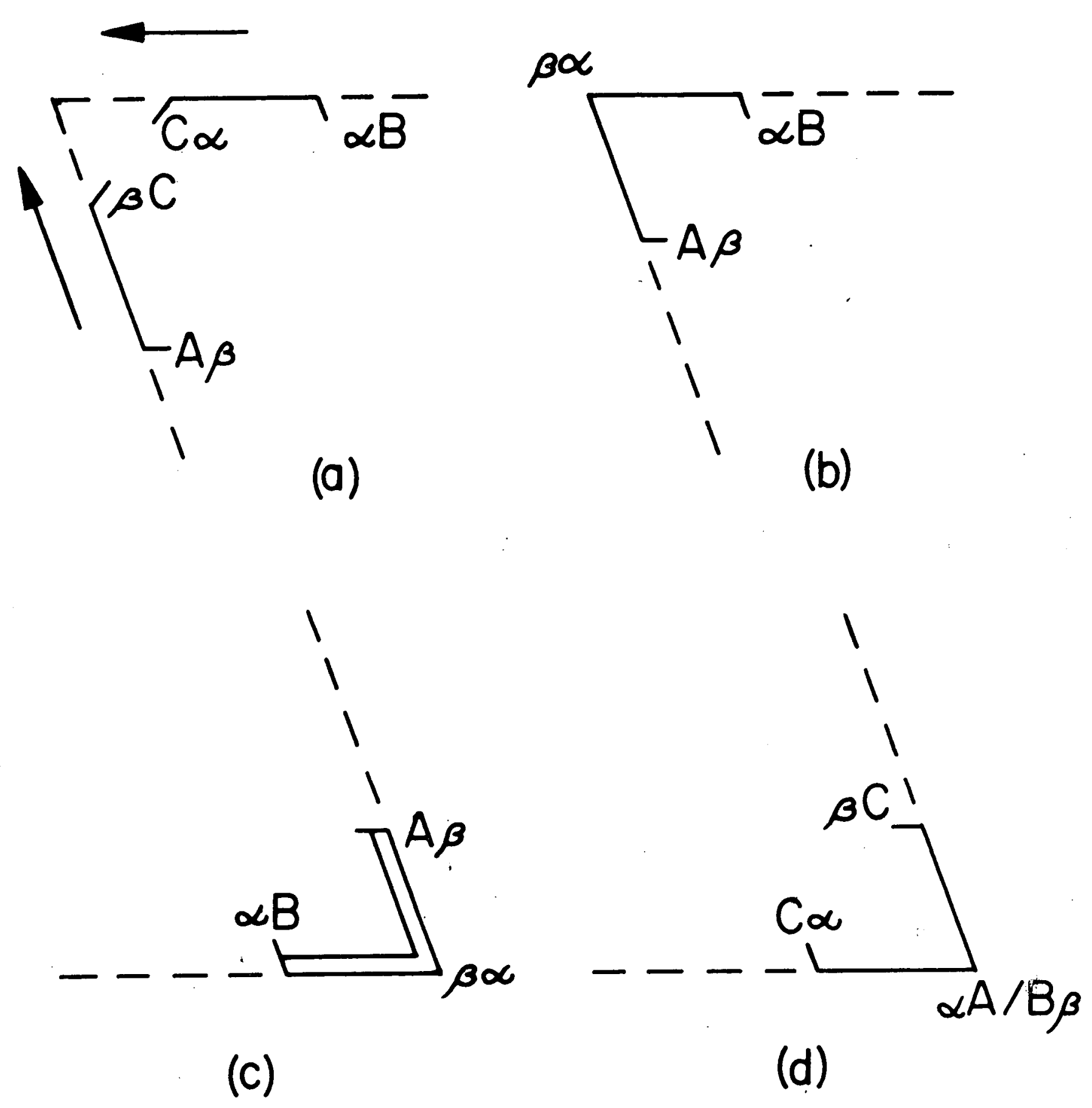
long jog along $C B$

(a)

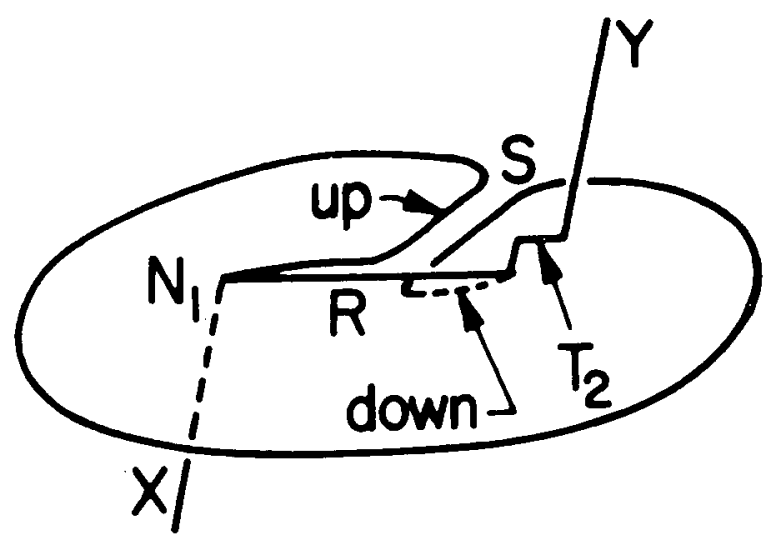

(c)

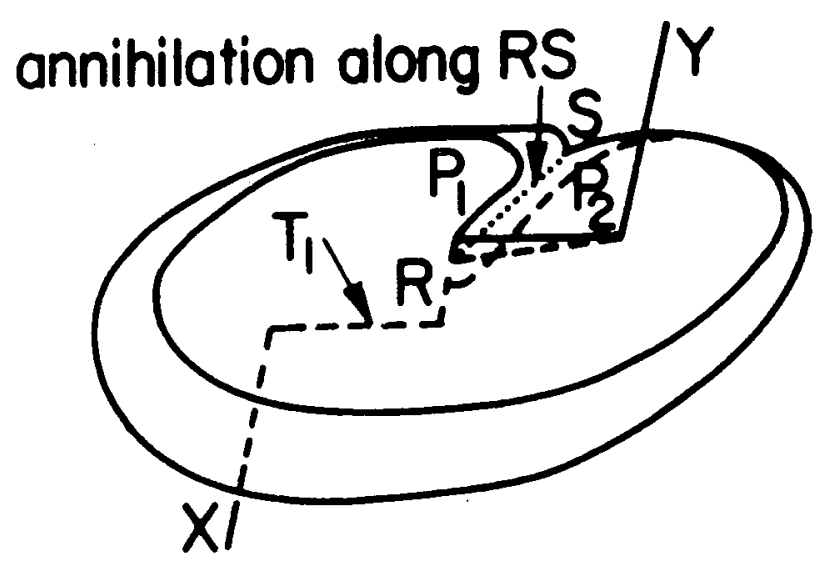

(e)

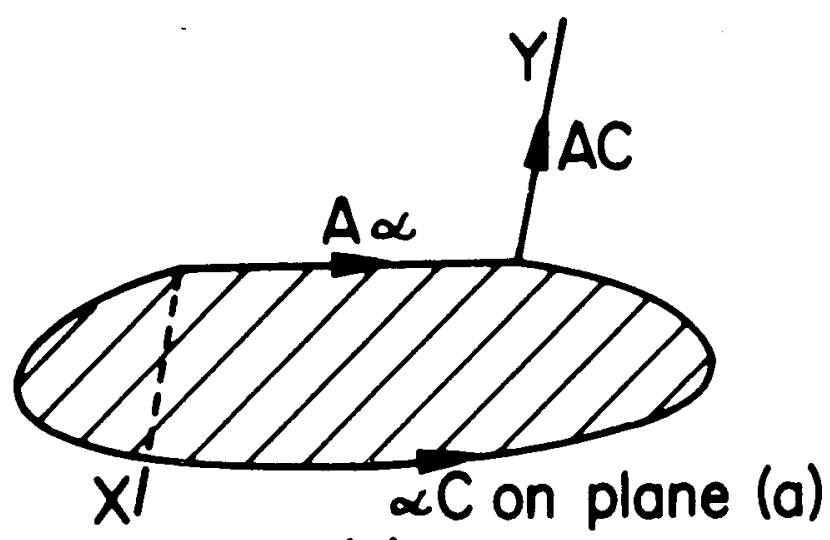

(b)

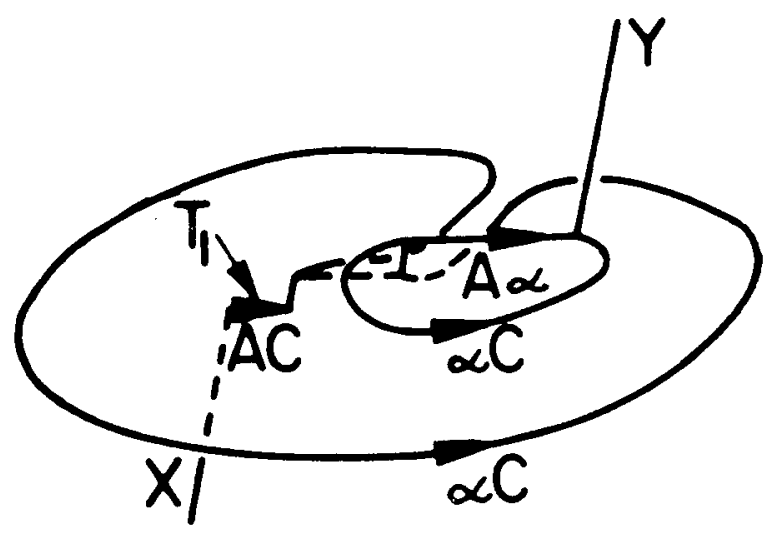

(d)

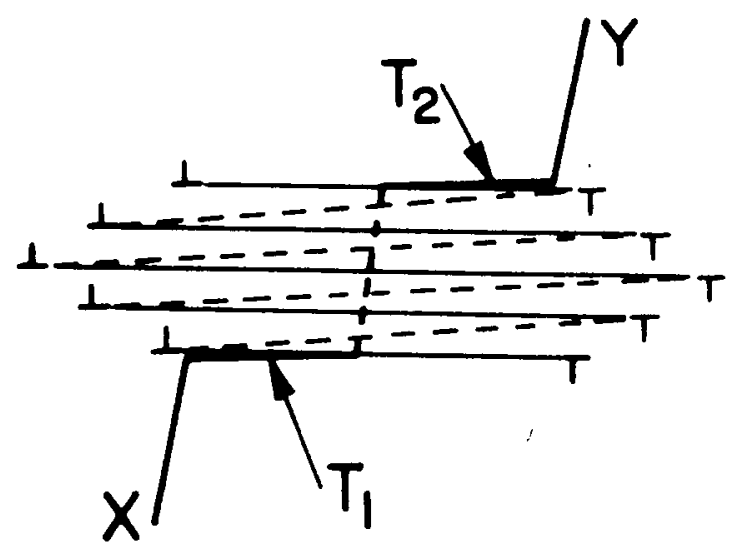

(f) 


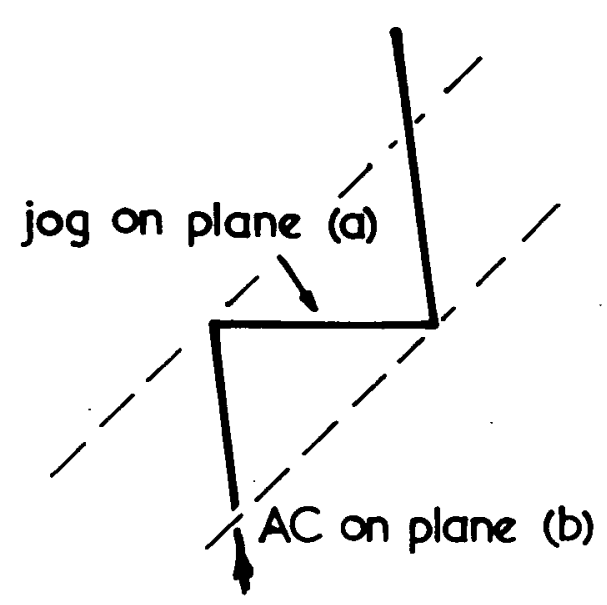

a.

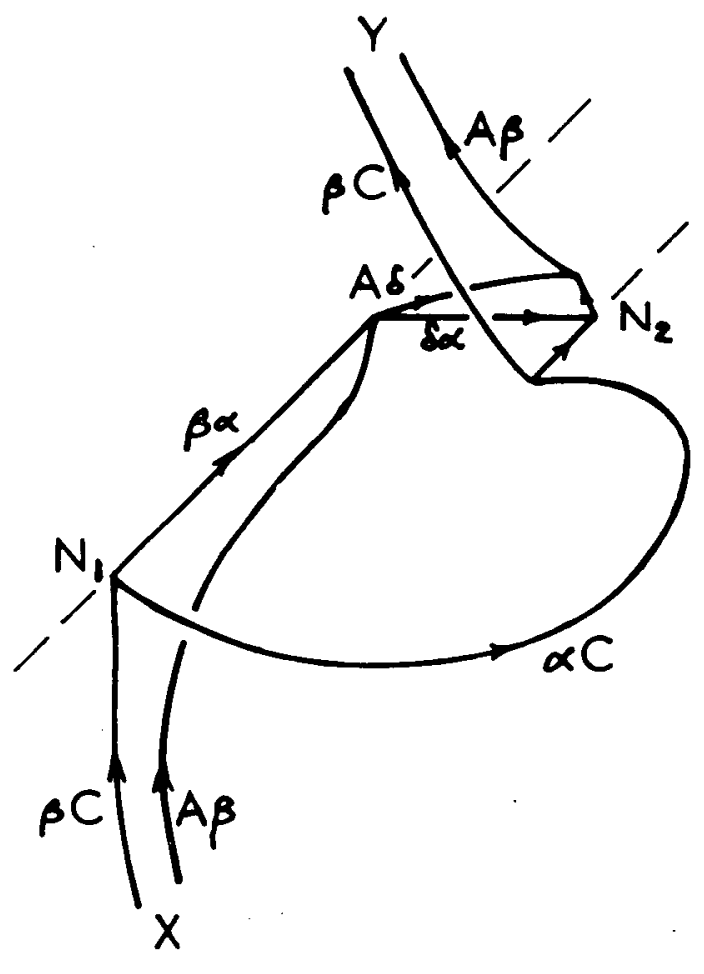

c.

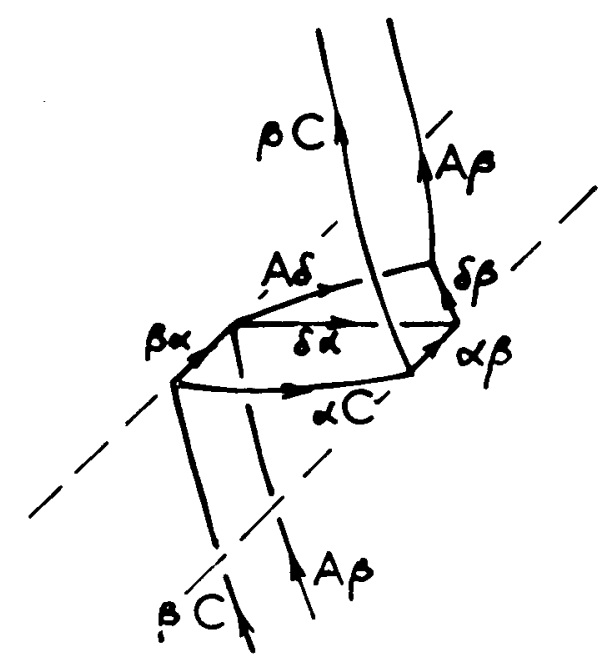

b.

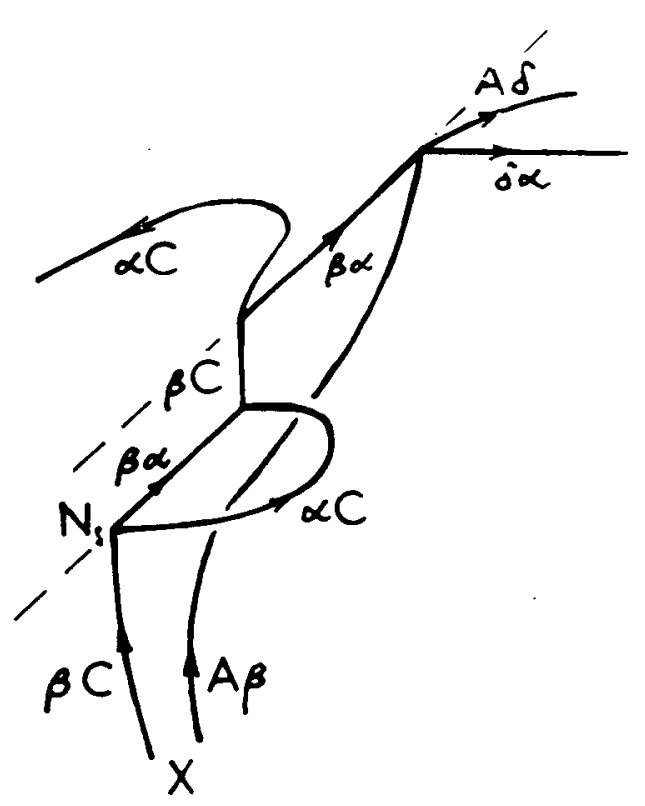

d. 


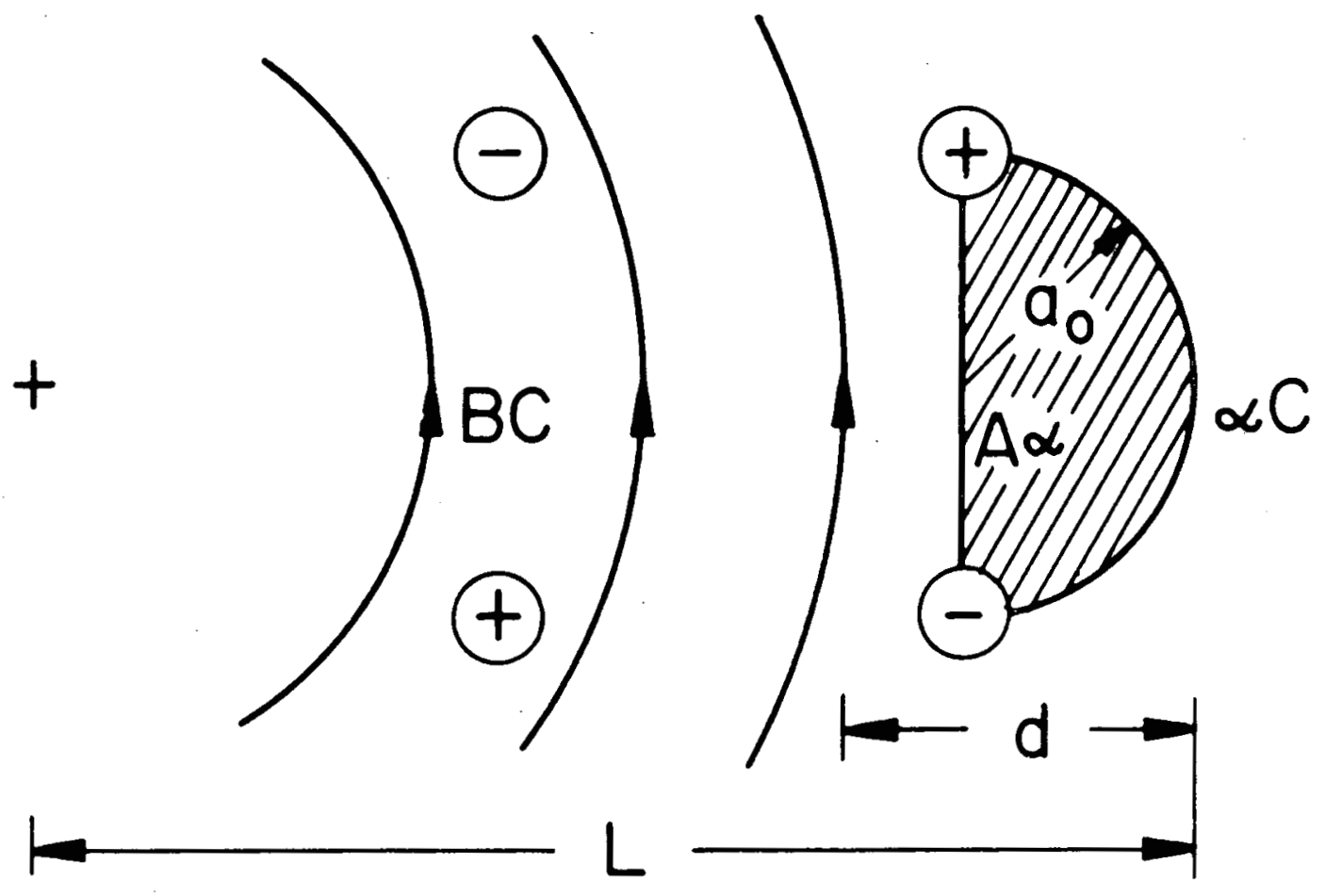

$\Theta$

$\oplus$

(a)

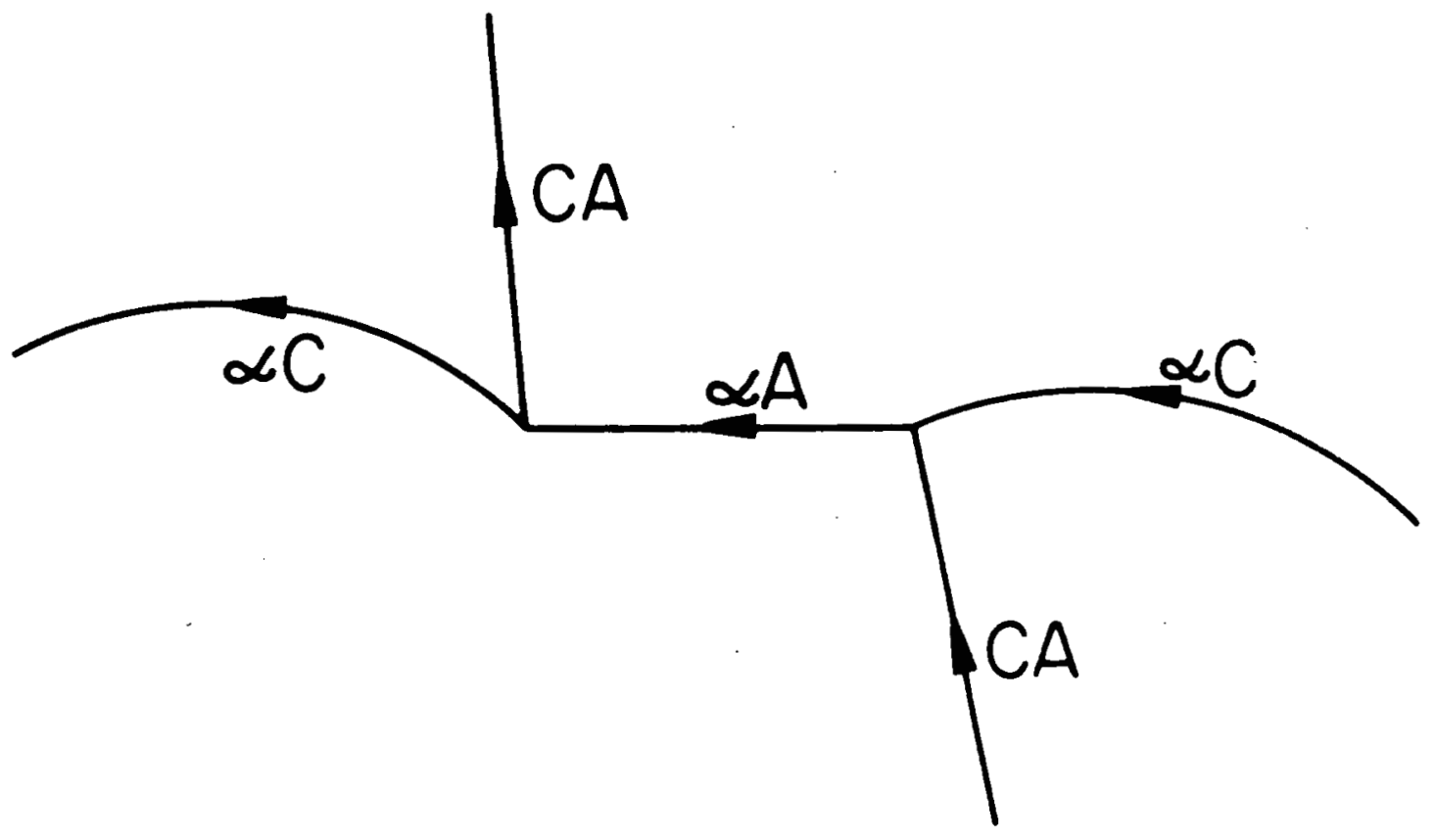

(b) 